\title{
Turbulence characteristics of flow in an open channel with temporally varying mobile bedforms
}

\author{
Prashanth Reddy Hanmaiahgari ${ }^{*}$, Vesselina Roussinova ${ }^{2}$, Ram Balachandar $^{3}$ \\ ${ }^{1}$ Department of Civil Engineering, IIT Kharagpur, Kharagpur, 721302, India. \\ ${ }^{2}$ Department of Mechanical Engineering, University of Windsor, Windsor, ON, N9B 3P4, Canada. E-mail: vtr@uwindsor.ca \\ ${ }^{3}$ Department of Civil and Environmental Engineering, University of Windsor, Windsor, ON, N9B 3P4, Canada. \\ E-mail: rambala@uwindsor.ca \\ *Corresponding author. E-mail: hpr@civil.iitkgp.ernet.in
}

\begin{abstract}
Turbulence of flow over mobile bedforms in natural open channels is not yet clearly understood. An attempt is made in this paper to determine the effect of naturally formed mobile bedforms on velocities, turbulent intensities and turbulent stresses. Instantaneous velocities are measured using a two-dimensional particle image velocimetry (PIV) to evaluate the turbulence structure of free surface flow over a fixed (immobile) bed, a weakly mobile bed and a temporally varying mobile bed with different stages of bedform development. This paper documents the vertical distribution of velocity, turbulence intensities, Reynolds shear stress and higher-order moments including skewness and turbulent diffusion factors. Analysis of the velocity distributions shows a substantial decrease of velocity near the bed with increasing bedform mobility due to increased friction. A modified logarithmic law with a reduced von Kármán constant and increased velocity shift is proposed for the case of the mobile bedforms. A significant increase in the Reynolds shear stress is observed in the mobile bedforms experiments accompanied by changes over the entire flow depth compared to an immobile bed. The skewness factor distribution was found to be different in the case of the flow over the mobile bedforms. All higher-order turbulence descriptors are found to be significantly affected by the formation of temporally varying and non-equilibrium mobile bedforms. Quadrant analysis indicates that sweep and outward events are found to be dominant in strongly mobile bedforms and govern the bedform mobility.
\end{abstract}

Keywords: Turbulence; Open channel; Bedforms; Higher-order moments; PIV; Quadrant analysis.

\section{INTRODUCTION}

In a natural open channel flow, the motion of the bed particles is initiated when the stresses induced on the bed exceed a critical threshold value. The instability of the bed manifests itself in the formation of various bedforms. These bedforms at certain conditions can become fully formed or can continue to be in a transient state. The size and shape of the bedforms depend strongly on the flow characteristics. In rough wall boundary layer flows, the principal effect of the fixed surface roughness is a change in the velocity and turbulence near the surface. In an open channel flow, when the bed particles start to move they interact with the overlying turbulent flow in a very complex manner affecting the overall channel resistance. The interaction between the bed morphology, flow and associated sediment transport continues to be an area of active research. Flow over bedforms is also of interest in the fields of geophysics and river mechanics, where the feedback between the sediment transport and landscape evolution is a critical component in the design of sustainable river restoration strategies.

Despite the advancement in our understanding of flow and turbulence in open channels, the flow behaviour over permeable sand beds have not been investigated in sufficient detail. In particular, it is not yet clear how the permeability of the bed influences the turbulence properties. Furthermore, it is not clear how the overlying flow interacts with the bed particles resulting in organized bed load movement. Most of the available experimental and numerical studies on bedforms have characterized the flow and turbulence over fixed dunes or ripples where the role of the mobile sediment and continuous deformation of the bed has been ignored (Balachandar and Patel, 2008; Robert and Uhlman, 2001).

To understand the turbulence structure of flow in open chan- nels, early experimental studies were performed with impermeable smooth and fixed rough beds. These investigations have produced increasingly detailed and consistent information about the velocity and turbulence structure of flow. All these studies have identified the applicability of the logarithmic law of the wall for smooth and rough open channel flows. In the review paper by Nezu (2005), the validity of the logarithmic law in 2D uniform open channel flows and the universality of the von Kármán constant $(\kappa)$ has been established (irrespective of the flow conditions). Gupta and Paudyal (1985) noted a reduced von Kármán constant value of 0.28 for a porous immobile bed compared to the classical value of 0.41 for an impervious bed. Balachandar and Patel (2002) demonstrated that the velocity profiles measured in a rough open channel flow conform to the classical log-law with an appropriate velocity shift. Tachie et al. (2004) showed that surface roughness increases the skin friction coefficient and thickness of the roughness sublayer in an open channel flow.

Open channel flows with mobile beds, with and without bedforms, add more complexity to the overlying turbulent flow. The sediment is transported mainly as bed load which continuously deform the bed, creating various bed patterns. It is difficult to insulate a single type of bedform during such transition due to the constant change of the flow and sediment parameters. Most of the laboratory experiments are carefully designed to insulate the effect of a single bedform. In rivers, bed patterns often arise which cannot fall under a single bedform category. Investigation of the mean velocity distributions in the presence of bed-load transport by Nikora and Goring (2000) and Bennett et al. (1998) among many others, have shown a reduction of the von Kármán constant. However, few earlier studies confirmed the universal validity of the von Kármán constant. It was observed in mobile bed experiments that velocity measurements 
and exact elevations above the prescribed bed level are difficult to identify on moving beds. Gyr and Schmid (1997) observed that mobile beds greatly increase the bed shear stress compared to a weak bed load transport. It is found to be very challenging to predict bedform evolution which is crucial for accurately understanding bedform dynamics (Nelson et al. 2011). Further, Nelson et al. (2011) proposed that the form roughness of bedforms has an extremely significant effect on the flow depth for a given discharge. Schindler and Robert (2005) described flow and turbulence characteristics above transient bedforms and found that ejections dominate over sweeps in terms of frequency of occurrence while sweeps dominate ejections in magnitude. They also found that turbulence intensities and Reynolds stresses are similar across transitions at individual flow depths, however, greatest in the outer layer. Singh et al. (2010) used gravel bed of size $d_{50}=7.7 \mathrm{~mm}$ and carried out spectral analysis of time series of velocities of flow. They found that at high frequencies, an inertial subrange with $-5 / 3$ Kolmogorov scaling was observed and at low frequencies, another scaling range with spectral slope of approximately -1.1 was found. Keylock et al. (2013) studied the turbulence structure above a moving gravel bedform. They found that flow over bedforms consists of boundary layer superimposed with wake turbulence and surface layer, and suggested to use LES as compared to other turbulence closure models for modelling the flow field.

Different types of coherent structures (e.g., spanwise vortices, kolk boil vortices) occur in open channel flows and influence the interaction between the bed and the overlying flow. Higher-order velocity moments provide useful statistical information on the temporal distribution of the fluctuations around the mean velocity and contain information related to coherent structures (Keirsbulck et al., 2001; Roussinova et al., 2010). Near the bed, the point of change of sign in the skewness profile is related to the crossover from sweep to ejection motions. Balachandar and Bhuiyan (2007) showed that higher-order moments and ejection events in open channel flow are sensitive to the wall roughness and their effects are prevalent throughout the depth and they have also shown that the relative contributions of ejections and sweeps to the Reynolds stress are quite well determined by the third-moment of the velocity fluctuations, while the fourth-order moment (flatness factor) describes the intermittency of turbulence. Turbulence diffusion factors and turbulent fluxes are an important component of the momentum budget and they provide evidence for the transport of turbulent stresses within the flow.

The study of the flow in open channels with hydraulically rough bed is generally made using the time averaged NavierStokes (RANS) equations. However, RANS equations are not practical near hydraulically rough beds since the time averaged flow is spatially heterogeneous. To overcome the above limitation, Nikora et al. (2007a, 2007b) proposed a double averaging methodology in which time averaged hydrodynamic equations are spatially averaged along a volume or area lying in the plane parallel to the mean bed surface. This leads to a new set of hydrodynamic equations that contain additional terms such as form-induced stresses. For the flow region below the roughness tops, both form and viscous drag terms appear in the equations. In this paper, only time-space averaging of instantaneous velocities has been implemented without calculating the form induced stresses and all time-space averaged quantities are denoted with a single over bar and angle brackets.

The main objective of the present study is to evaluate the effect of a hydraulically rough mobile bed with temporally varying bedforms on the turbulence intensities, Reynolds stresses and higher-order moments. To this end, particle image velocimetry (PIV) measurements were conducted in an open channel to evaluate the turbulence structure of flow over a fixed bed, a weakly mobile bed and a temporally varying mobile bedform. Measured velocity fields of a given bed condition were time averaged and turbulence statistics were obtained. Turbulence statistics were then spatially averaged over a PIV interrogation window to study the effect of the non-equilibrium bedforms on turbulence intensities, shear stresses and third-order moments such as skewness and turbulent diffusion factors. Quadrant analysis was also carried out to determine the contribution of events from different quadrants to the Reynolds shear stress.

\section{EXPERIMENTS}

\section{Experimental set-up and PIV system}

The experiments were conducted in a rectangular open channel flume of $12.0 \mathrm{~m}$ length, $0.61 \mathrm{~m}$ width, and $1.0 \mathrm{~m}$ height with a fixed small bed slope of $0.0002 \mathrm{~m} / \mathrm{m}$. The sand bed was $5.8 \mathrm{~m}$ long and $0.15 \mathrm{~m}$ thick, spanning the entire width of the flume. A ramp was built at the start of the sand bed to minimize any disturbances to the approaching flow (Fig. 1). The median size diameter $\left(d_{50}\right)$ of the sand grains $=0.7 \mathrm{~mm}$ was chosen to avoid cohesion effects (USCS soil classification). A centrifugal pump was used to recirculate the water in the flume. The test section was located $3.5 \mathrm{~m}$ downstream from the start of the sand bed. The flow and bed conditions are listed in Table. 1. A Cartesian coordinate system is positioned at the level of the roughness where the streamwise flow direction is considered along the $x$-axis while $y$-axis is in the vertical direction. The PIV measurements were conducted in a vertical central plane of the channel (to avoid secondary currents effects) and the size of the field-of-view (FOV) was $0.075 \mathrm{~m} \times 0.075 \mathrm{~m}$. A dual pulse Nd-YAG laser of $532 \mathrm{~nm}$ wavelength with a $300 \mathrm{~mJ} /$ pulse was

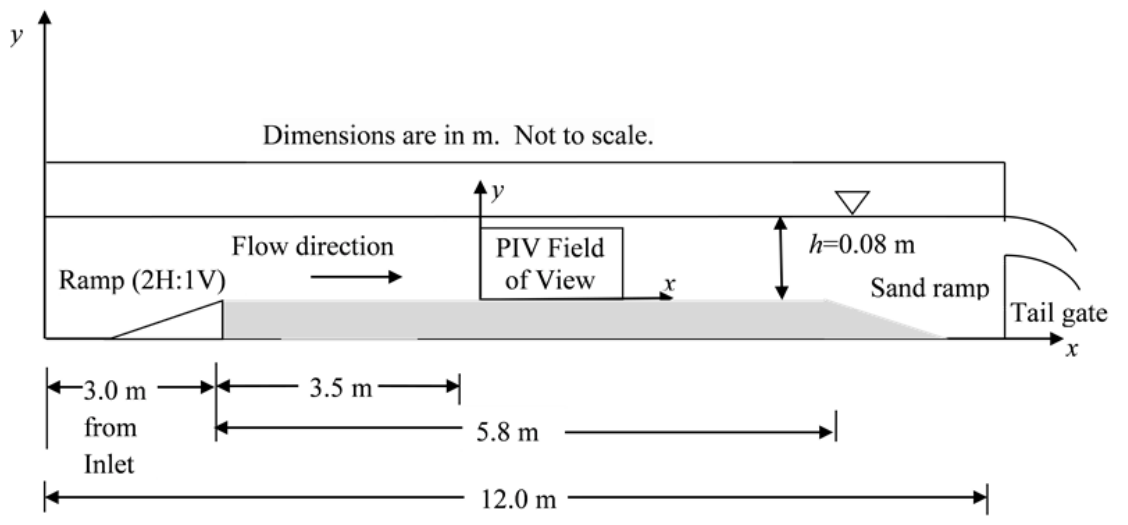

Fig. 1. Schematic of experimental set-up. 
Turbulence characteristics of flow in an open channel with temporally varying mobile bedforms

Table 1. Summary of the experimental conditions (flow depth $(h)=0.08 \mathrm{~m}$ is constant in all the experiments).

\begin{tabular}{|c|c|c|c|c|c|c|c|c|c|}
\hline Runs & Bed condition & $\begin{array}{l}U_{\max } \\
(\mathrm{m} / \mathrm{s})\end{array}$ & $\begin{array}{c}\text { Reynolds } \\
\text { number } \\
R_{e}\end{array}$ & $\begin{array}{c}\text { Froude } \\
\text { number } \\
F_{r}\end{array}$ & $\begin{array}{l}\text { Friction } \\
\text { velocity } \\
\left(u_{* 1}\right)^{*} \\
(\mathrm{~m} / \mathrm{s})\end{array}$ & $\begin{array}{c}\text { Friction } \\
\text { velocity } \\
\left(u_{* 2}\right)^{* *} \\
(\mathrm{~m} / \mathrm{s})\end{array}$ & $\kappa$ & $R_{x}$ & $\begin{array}{c}\delta \\
(\mathrm{m})\end{array}$ \\
\hline IM1 & Immobile & 0.240 & 16696 & 0.24 & 0.0137 & 0.0100 & 0.41 & 30435 & 0.0586 \\
\hline IM2 & Immobile & 0.262 & 18226 & 0.27 & 0.0153 & 0.0105 & 0.40 & 31957 & 0.0580 \\
\hline IM3 & Immobile & 0.276 & 19200 & 0.28 & 0.0157 & 0.0110 & 0.42 & 33478 & 0.0600 \\
\hline IN & Incipient motion & 0.31 & 21565 & 0.30 & 0.0169 & 0.0140 & 0.35 & 43041 & 0.0543 \\
\hline WM & $\begin{array}{l}\text { Weak bed movement } \\
\text { (minor bedforms) }\end{array}$ & 0.345 & 24000 & 0.34 & 0.0172 & 0.0163 & 0.33 & 52715 & 0.0560 \\
\hline SM1 & Mobile bedforms & 0.384 & 26713 & 0.37 & 0.0246 & 0.0245 & 0.26 & 74550 & 0.0632 \\
\hline SM2 & Mobile bedforms & 0.398 & 27687 & 0.38 & 0.0270 & 0.0247 & 0.27 & 76087 & 0.0703 \\
\hline
\end{tabular}

* $u_{* 1}$ is determined using Krogstad et al., (1992) method

$u_{* 2}$ is determined using Reynolds stress method

used to illuminate the flow. The laser sheet was formed through a spherical lens and expanded through a cylindrical lens. The thickness of the laser sheet was approximately $1 \mathrm{~mm}$ and the laser sheet entered the flow through the free surface allowing simultaneous measurements of the streamwise and wall-normal velocity components. The particle images were recorded using a 4 MP camera synchronized with the laser using a TSI PIV laser pulse synchronizer. The camera was mounted with a $28-$ $105 \mathrm{~mm}$ Nikor lens and adjusted to give the desired FOV. The camera resolution was 2048 pixels $\times 2048$ pixels, which results in each pixel representing $0.037 \mathrm{~mm}$ of the flow. The flow was continuously seeded with spherical hollow glass particles of mean diameter $12 \mu \mathrm{m}$ with a specific gravity of 1.13 . Similar particles have been used in previous studies by Shinneeb et al. (2004) and Roussinova et al. (2010), and the suitability of the particles to faithfully follow the flow has been verified.

For each test, a series of 2000 pairs of images were recorded at a frequency of $1.04 \mathrm{~Hz}$. The time separation between the pairs was maintained in such a way that the maximum particle displacement was 8 pixels. Time separation between consecutive pairs were acquired at a frequency of $1200,1100,900,860$, 800,800 and 750 micro seconds for experiments IM1, IM2, IM3, IN, WM, SM1 and SM2 respectively. The images were analyzed with the TSI Inc Insight $3 \mathrm{G}$ software. The velocity field was determined from the particle displacement calculated between two consecutive recorded images using a twodimensional cross-correlation technique. Each frame was split up into small interrogation areas where the correlation analysis is performed using a fast Fourier transform. The details of the correlation technique and the methodology are reported in Shinneeb et al. (2004) and Roussinova et al. (2010). Initially, the particle displacements were determined by using an interrogation size of 64 pixels $\times 64$ pixels. The peak of the correlation was identified by a Gaussian curve-fitting technique. Using the estimations of prediction, refinement of the velocity vector was obtained in a 32 pixel $\times 32$ pixel $(1.2 \mathrm{~mm} \times 1.2 \mathrm{~mm})$ interrogation area. A $50 \%$ overlap of the interrogation areas was used to satisfy the Nyquist criterion. The resulting field consists of 127 $\times 127$ vectors in each instantaneous image. Following the correlation analysis, outlier vectors were identified and replaced using the cellular neural network method with a variable threshold technique, as proposed by Shinneeb et al. (2004). The rejected vectors were estimated to be less than $5 \%$. The uncertainty of the PIV measurements due to the random error associated with the sub-pixel estimator combined with the 2000 statistically independent velocity fields acquired per flow configuration and ensemble averaged in order to produce both velocity and turbulence statistics, was estimated to be $1-2 \%$ for the mean statistics and 3-7\% for the turbulent fluctuations and Reynolds shear stress. Note that these ranges accommodate the variation of the sampling error due to the spatial variations of the mean and turbulence statistics in the present flow configurations. In addition, during the dune movement across the image, the data which was masked by the dune and the region of light reflection on the bedform has been neglected. In addition, at any depth, if data fall outside three times the standard deviation bound on either side was removed from the analysis. In mobile bedform experiments very few particles are found to be in suspension, which do not appreciably affect the velocity results presented herein.

\section{Experimental conditions}

Flow is uniform in the flume at the beginning of the experiment and the normal depth of flow in the measurement section was $0.08 \mathrm{~m}$, however, the moment mobile bedforms being developed, the flow becomes quasi-uniform. The channel aspect ratio (channel width /flow depth) is equal to 7.6 which is larger than the suggested value of five (Nezu and Nakagawa, 1993) established as a criteria for the effect of the secondary flows. A higher velocity was maintained for the mobile bedforms compared to the immobile bed. The flow Reynolds numbers $R_{e}=U_{\max } h / v$ based on the total depth $(h)$ and maximum velocity $\left(U_{\max }\right)$ are shown in Table 1 . The Froude number calculated for the tests correspond to the subcritical flow regime. The Reynolds number based on the streamwise distance of the measurement section $\left(R_{x}=u_{*} x / v\right)$ is found to be in the range of $3 \times 10^{4}-3.5 \times 10^{4}, 3.5 \times 10^{4}-6 \times 10^{4}$ and greater than $7 \times 10^{4}$ for immobile bed, incipient motion and mobile bedforms experiments, respectively, where $x$ values are measured from the starting of the sand bed. The range of $R_{x}$ values used in the proposed study is similar to the reported fully developed flow experiments on hydraulically rough surfaces. In addition, the minimum flow development length computed using the formula $76 h-0.0001 R_{e} h / F_{r}$ proposed by Kirkgöz and Ardichoğlu (1997) is $5.5 \mathrm{~m}$ which is less than the distance between the entrance and the test section, i.e., $6.5 \mathrm{~m}$. therefore flow development length provided is adequate in the present experiments.

The estimates of the friction velocities are given in Table 1. Two different approaches are used to calculate the friction velocity $\left(u_{*}\right)$. The first method fits the velocity profile in the outer layer using equation proposed by Krogstad et al. (1992) developed for the case of a rough turbulent boundary layer. This value is denoted as $u_{* 1}$ in Table 1 . The friction velocity was also obtained from the Reynolds shear stress profile in the region $0.2<y / h<0.7$ where the contribution from the vis- 
cous stress is negligible. The value of the Reynolds shear stress was extrapolated to the wall and this value was used to estimate the friction velocity $\left(u_{* 2}\right)$ as shown in Table 1 . The friction velocity $\left(u_{* 2}\right)$ computed by the above method (extrapolated Reynolds shear stress) is used to compute von Kármán constant, the velocity shift $\left(\Delta U^{+}\right)$from the smooth bed log-law and used in scaling of turbulent intensities, shear stresses and higher order moments. It was observed that friction velocity calculated from Krogstad et al. (1992) equation using velocity information in the outer layer yields higher values of the friction velocity than obtained from the Reynolds shear stress method.

The critical shear stress $\left(\tau_{o c}\right)$ for the present sand bed $\left(d_{50}=\right.$ $0.7 \mathrm{~mm}$ ) was computed from the Shields diagram and it was equal to $0.340 \mathrm{~N} / \mathrm{m}^{2}$. Sand bed corresponding to subcritical bed shear stress is called immobile (fixed), bed shear stress $\tau_{o}$ close to critical turbulent shear stress $\tau_{o c}$ is called weakly mobile bed (Nikora and Goring, 2000) and bed shear stress $\tau_{o}$ much greater than $\tau_{o c}$ is called a strongly mobile bed. In Table 1, IM1, IM2 and IM3 correspond to immobile beds, while incipient motion occurs visibly in test IN. These notations are used in all the forthcoming figures. Weak bed formations begin to develop in WM with height of bedforms varying between 5 and $8 \mathrm{~mm}$. Mobile dunes are formed in experiments SM1 and SM2. Average dune height and wave length measured in SM1 are $0.019 \mathrm{~m}$ and $0.30 \mathrm{~m}$, respectively. Similarly, the average dune height and wave length formed in SM2 are $0.028 \mathrm{~m}$ and $0.41 \mathrm{~m}$, respectively. Measured dune velocities are in the range of 0.35 to $1.8 \mathrm{~mm} / \mathrm{s}$. The dune velocity reaches its maximum $(1.8 \mathrm{~mm} / \mathrm{s})$ in experiment SM2.

\section{RESULTS AND DISCUSSION Mean flow analysis}

In the following sections, the superscript " + "' denotes inner scaling where the distance is normalized with the viscous length scale $u_{*} / v$ and the mean velocity is scaled with the friction velocity $u_{*}$. Faruque and Balachandar (2011) proposed that the proper outer velocity scale in turbulent boundary layers should be the free stream velocity $U_{\max }$. Following this idea, $U_{\text {max }}$ is suggested as the appropriate velocity scale and $h$ is used as the characteristic length scale. Unlike friction velocity, $U_{\text {max }}$ and $h$ are directly measured quantities.

\section{Mean velocities in outer variables}

The double averaged velocity distributions of the streamwise velocity in outer variables are shown in Figs. 2(a) and 2(b) over immobile and mobile bedforms, respectively. It is clear from
Fig. 2(a) that an increase in the flow rate (Reynolds number) does not change the normalised velocity distribution for the fixed bed (IM1, IM2 and IM3) as well as during the incipient motion (IN). As the flow velocity increases on the immobile bed, the effect of the roughness is localized near the bed and the thickness of the roughness sublayer is small compared to the value of $h$. In Fig. 2(b), an increase of the flow velocity causes the velocity to decrease near the bed. Fig. 2(b) also shows that $d u / d y$ decreases with increase in mobility of the bed. The influence of the mobile bedforms on the velocity distribution is strong near the bed. However, the entire distribution is effected as seen in tests SM1 and SM2. Energy is extracted from the mean flow and transferred to the bed particles to sustain bed mobility which causes the decrease in velocities near the bed.

Log-law

The velocity distributions in the logarithmic law format are shown in Fig. 3. The velocity distribution of flow over a smooth bed (Roussinova et al. 2008) is also included which conforms to the log-law. The velocities are in the increasing order in the experiments IM1, IM2, IM3, IN, WM, SM1 and SM2 as shown in Table 1. The data of IM1, IM2 and IM3 are clustered together. The downward shift from the smooth-wall log-law noticed in the present study is consistent with the increasing bed roughness.

The von Kármán constant $\kappa$, relates the distribution of flow velocity and friction velocity. The reported $\kappa$ values varies between 0.37 and 0.43 for wall bounded shear flow and $\kappa$ value decreases with increasing roughness Reynolds number (Andreas et al., 2006). It has been reported earlier that $\kappa$ decreases with increasing bed movement (Bennett et al., 1998; Nikora and Goring, 2000). By using the traditional value of $\kappa$, it was found that the classical logarithmic law is not applicable to flows with the incipient bed motion, weak bed motion and strong bed motion (mobile bedforms). To this end, $\kappa$ was evaluated using the present experimental data. The following equation (Andreas et al., 2006; Nikora and Goring, 2000) has been used to compute the von Kármán constant and surface roughness for each experiment.

$$
U=\frac{u_{*}}{\kappa} \ln \left(\frac{y+\Delta}{y_{o}}\right)
$$

Here, $U$ is the mean velocity at an elevation y above the reference bed, $u_{*}$ is the friction velocity, $\boldsymbol{y}$ is measured from the tops of the particles, which taken as origin of the co-ordinate system, whereas $\Delta$ and $y_{o}$ are distance (height) measured above
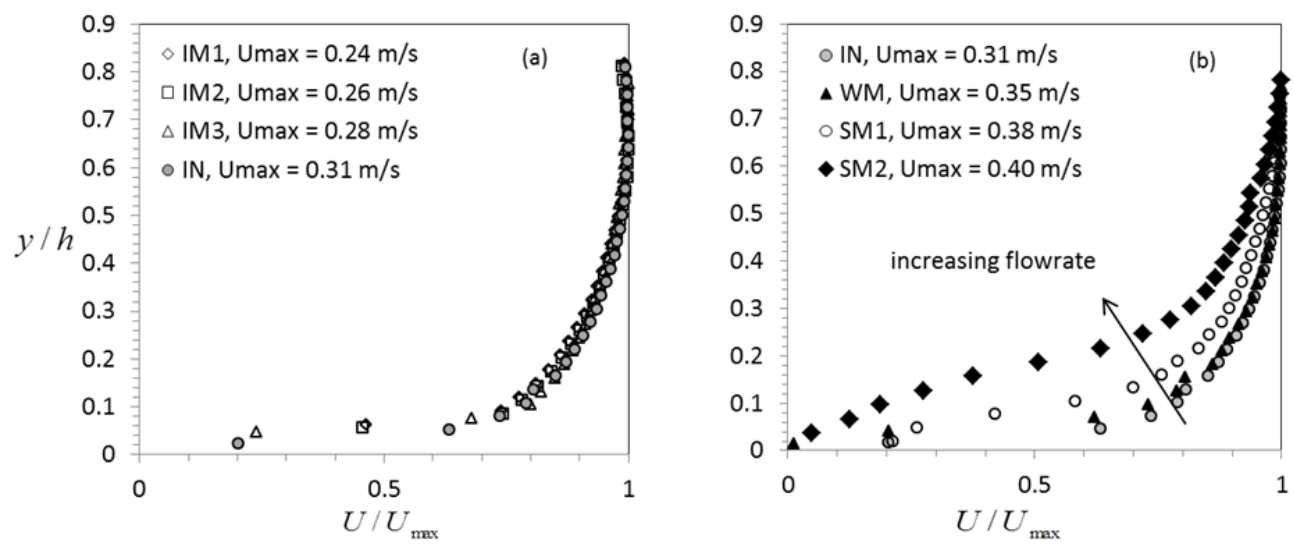

Fig. 2. Mean velocity distributions of (a) immobile bed and (b) mobile bedforms. 


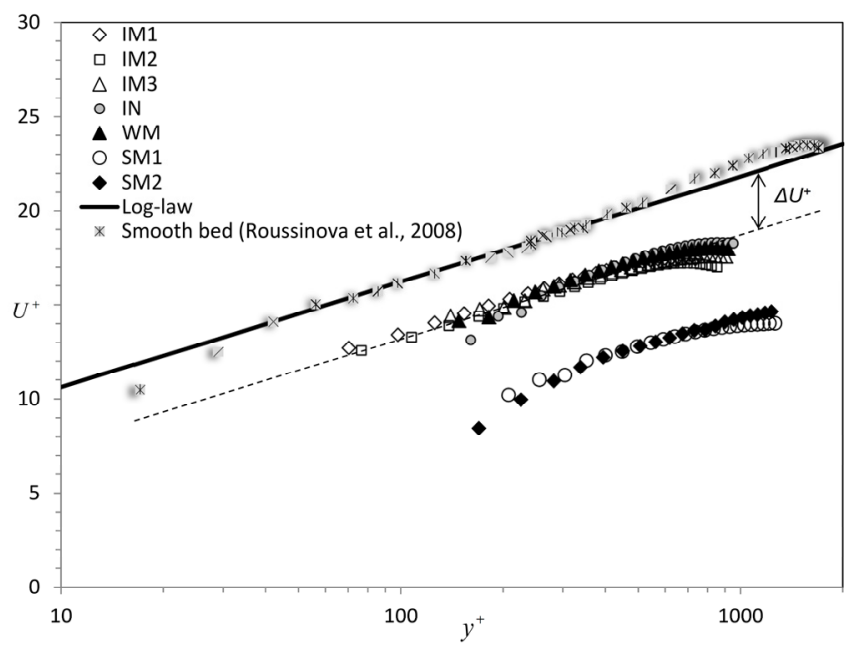

Fig. 3. Velocity distributions of smooth bed, immobile and mobile bedforms.

the reference datum, here $\Delta$ and $y_{o}$ are always positive and $\boldsymbol{y}$ is negative below the top of the particles, $y_{o}$ is the surface roughness such that $U\left(y_{o}=y+\Delta\right)=0$, reference datum is $\Delta$ distance below the tops of particles (origin of the co-ordinate system) $\Delta$ is the displacement height (which is equal to zero for smooth flatbed) which is $0.35 d_{50}$ for sand grain roughness. Velocity distribution in the region $0.05 \leq y / h \leq 0.2$ is used to best fit the experimental data and determine $\kappa$ and $y_{o}$. The computed values of $\kappa$ are presented in Table 1. For rough porous open channel flow without bed movement the estimated $\kappa$ values vary between 0.40 and 0.42 . The estimated $\kappa$ values are between 0.35 to 0.32 for incipient bed and weak bed motion, and are similar to those reported by Bennett et al. (1998). For strongly mobile bedforms, $\kappa$ values are further decreased. The results demonstrate that the von Kármán constant decreases due to increase of the thickness of roughness sublayer as the mobility of bedforms increases.

Velocity defect equation in a fully developed rough turbulent boundary layer proposed by Krogstad et al. (1992) is used to compute the friction velocity, wake parameter (П) and shift in the origin $(\varepsilon)$ by optimizing the measured velocity distribution in the outer region $y / h>0.1$. This method has been adopted earlier for the flow in uniform open channel flow on smooth and rough beds (Balachandar et al., 2001; Tachie et al., 2000). The evaluated values of the von Kármán constant shown in Table 1 were utilized. The non-dimensional quantity $\Pi$ is a measure of the deviation of the velocity distribution from the logarithmic law of the wall. The reported value of $\Pi$ varied from -0.27 to +0.2 for the smooth, uniform open channel flow. It is reported that the presence of sediment bed leads to the negative values of wake parameter. Their values are -0.104 , $-0.084,-0.170,-0.265,-0.383,-0.382$ and -0.431 for the experiments IM1, IM2, IM3, IN, WM, SM1 and SM2 respectively. In the present experiments, wake parameter (П) values are negative and their absolute value is increasing as the bed mobility and mobile bedforms size increases.

Downward shift $\left(\Delta U^{+}\right)$from the smooth bed profile may be obtained by applying the following Coles velocity defect law to the measured velocity distribution (Balachandar and Patel, 2002).

$$
\frac{U}{u_{*}}=\frac{1}{\kappa} \ln \frac{(y+\varepsilon) u_{*}}{v}+B-\Delta U^{+}+\frac{2 \Pi}{\kappa} \sin ^{2}\left(\frac{\pi(y+\varepsilon)}{2 h}\right)
$$

Eq. (2) was applied to compute velocity shift $\Delta U^{+}$for all runs since all other variables in Eq. (2) are known. The friction velocity $\left(u_{*}\right)$, wake strength parameter $(\Pi)$, and $\varepsilon$ were obtained by optimizing each set of experimental data following the Krogstad et al. (1992) method. The computed $\Delta U^{+}$values are listed in Table 2. It is observed that for immobile rough porous beds $\Delta U^{+}$values vary between 2.7 and 3.18. These values agree well with $\Delta U^{+}=3$ presented by Bigillon et al. (2006) for fixed non-porous rough beds. For incipient bed motion and weak mobile bedforms the computed values of $\Delta U^{+}$are slightly higher $(\approx 4.0)$. The $\Delta U^{+}$values are very high $\left(\Delta U^{+}>15.0\right)$ for strongly mobile bedforms. The roughness Reynolds number $\left(k_{s}^{+}\right)$was also calculated from the correlation given by Raupach et al. (1991) and the values are presented in Table 2. For $\Delta U^{+} \approx$ 3, 4 and 15 (immobile, weakly mobile bedforms and strong mobile bedforms) the estimated $k_{s}^{+}$values are $\approx 13,11$ and 148 , respectively. The flow is transitionally rough for immobile and weakly mobile bedforms, and completely rough in the case of strongly mobile bedforms $\left(k_{s}^{+}>70\right)$.

\section{Turbulence intensities}

Fig. 4(a) shows the vertical distribution of the streamwise turbulence intensity $\left(\left\langle\bar{u}_{r \operatorname{ms}}\right\rangle / U_{\max }\right)$ in outer scaling. There is no significant change of turbulence intensity in the outer layer in the immobile bed experiments (IM1 and IM2), which collapse onto each other and the smooth bed profile (Roussinova et al., 2008). Turbulence intensity near the free surface is higher in IM3 than IM1 and IM2. The present results agree well with the higher Reynolds number flow on an immobile rough bed (Faruque and Balachandar, 2011) which is also shown in Fig. 4(a). The streamwise turbulence intensity increases throughout the depth with increasing flow rate as indicated by the arrow. The peak values of streamwise turbulence intensity distributions in incipient bed motion (IN) and weakly mobile bedforms (WM) experiments are 0.23 and 0.26 , respectively, while the peak value of streamwise turbulence intensity of immobile beds is less than 0.10 . The increased spacing between turbulent intensity profiles of weakly mobile bedforms (WM) and immobile beds (IM) near the bed may be due to the relative importance of large eddy motion in the streamwise direction as compared to the small eddies. It is concluded that turbulence generation close to the bed in weakly mobile bedforms (WM) is higher than that of incipient bed (IN) due to the effect of the moving bed particles. The distributions of streamwise turbulence intensities in mobile bedforms are grouped separately (Fig. 4a). The peak streamwise turbulence intensity is around 0.325 and the increased level of turbulence is extended throughout the depth in both strongly mobile bedforms (SM1 and SM2) tests. Turbulence intensities are increasing near the bed with increase in size and mobility of the non-equilibrium mobile bedforms contrary to the decrease in mean velocities and decrease in velocity gradients (Fig. 2b). Flow over mobile bedforms may produce increased number of turbulent wakes of relatively small eddies (smaller than the sediment grains) in the lee side of grains and bedforms, which in turn increase the turbulence intensities. In addition, mobile zone of flow separation is either increasing or decreasing in temporally varying mobile bedforms which destabilizes the flow and increases the turbulence. Increase in grain collisions due to increased bed mobility will also contribute to the increase in turbulence intensities. 
Table 2. Mean velocity shifts and roughness Reynolds numbers.

\begin{tabular}{lccccc}
\hline Experiment & $\begin{array}{c}\text { Shift in Log-law } \\
\Delta U^{+}(\mathrm{m} / \mathrm{s})\end{array}$ & $\begin{array}{c}k_{s}^{+} \text {(Roughness } \\
\text { Reynolds number })\end{array}$ & $\begin{array}{c}\text { Surface roughness } \\
\varepsilon(\mathrm{m})\end{array}$ & $\begin{array}{c}\text { Downward shift in log- } \\
\text { law } \Delta U^{+}\end{array}$ & $\begin{array}{c}\text { Wake parameter } \\
(\Pi)\end{array}$ \\
\hline IM1 & 2.7 & 11 & 0.00067 & 2.72 & -0.104 \\
IM2 & 3.2 & 13 & 0.00049 & 3.18 & -0.084 \\
IM3 & 2.8 & 13 & 0.00045 & 2.83 & -0.170 \\
IN & 4.1 & 13 & 0.00130 & 4.06 & -0.265 \\
WM & 4.1 & 11 & 0.00145 & 4.05 & -0.383 \\
SM1 & 15.3 & 117 & 0.0074 & 15.32 & -0.382 \\
SM2 & 15.5 & 148 & 0.00670 & 15.51 & -0.431 \\
\hline
\end{tabular}

Distributions of the turbulence intensity, $\left\langle\bar{u}_{r m s}\right\rangle^{+}$in inner scaling are shown in Fig. 4(b). Nezu and Nakagawa (1993) proposed an empirical Eq. (3) describing the vertical distribution of the streamwise turbulence intensities in rough open channel flow. This equation is included in Fig. 4(b) for comparison.

$$
\bar{u}_{r m s}^{+}=\frac{U}{u_{*}} \frac{2.3 \exp (-y / h)}{\kappa^{-1} \ln (y / h)+\frac{2 \Pi}{\kappa} \sin ^{2}\left(\frac{\pi y}{2 h}\right)+\kappa^{-1} \ln \left(k_{s} / h\right)+8.5}
$$

The measured $\left\langle\bar{u}_{r m s}\right\rangle^{+}$values near the wall in the mobile bedforms are slightly above the immobile beds due to increased turbulence generation. The $\left\langle\bar{u}_{r m s}\right\rangle^{+}$distribution in the mobile bedforms reaches a maximum value of about 5.1 for $y / h<$ 0.2 . The rapid changes in the $\left\langle\bar{u}_{r m s}\right\rangle^{+}$values occur over a larger range $y / h<0.3$ in the mobile bedforms as compared to immobile beds where major changes occur in the range of $y / h<0.15$. The effect of turbulence due to the mobility of the
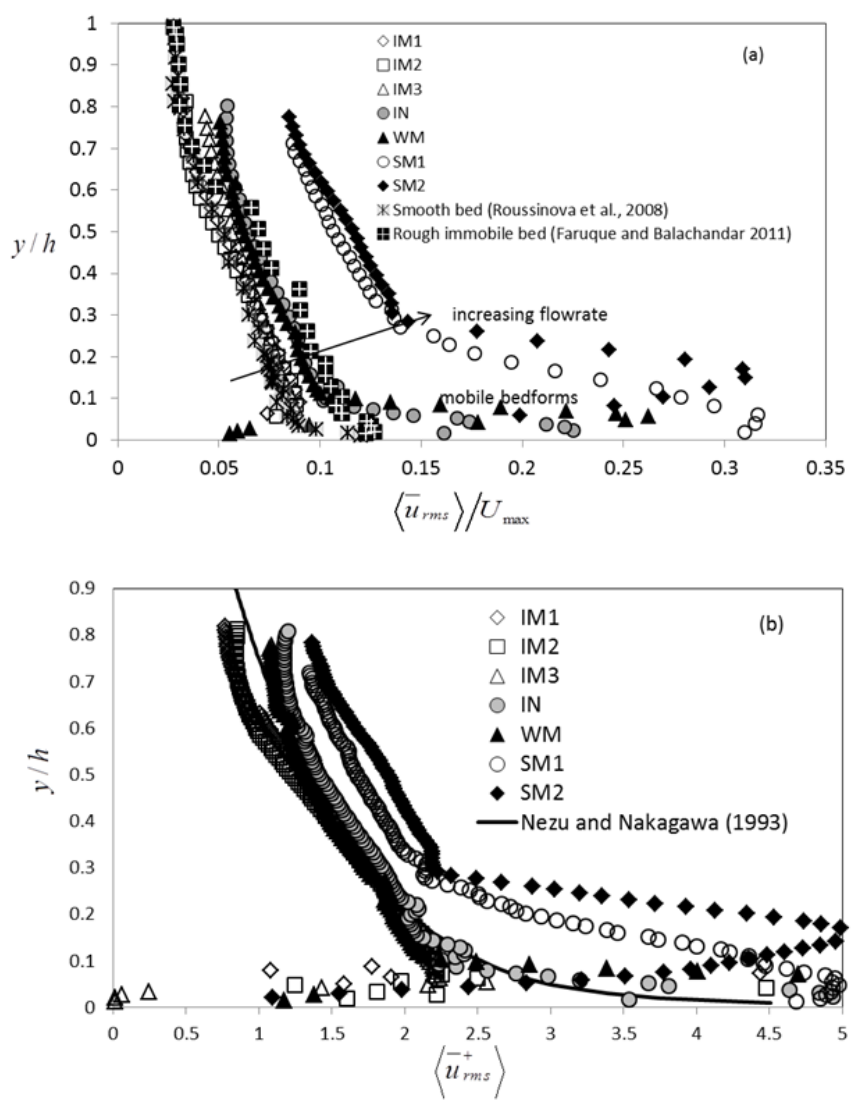

Fig. 4. Distributions of streamwise turbulence intensities for all runs (a) normalized with maximum velocities, and (b) normalized with shear velocities. bedforms and wall roughness is clearly distinct near the wall for $y / h<0.3$ and noticeable for $y / h>0.3$. The $\left\langle\bar{u}_{r m s}\right\rangle^{+}$distributions are shifted upwards as the flow rate increases for $y / h>0.3$ as shown in Fig. 4(b).

Fig. 5(a) shows the distributions of the vertical turbulence intensities $\left(\left\langle\bar{v}_{r m s}\right\rangle / U_{\max }\right)$ in outer scaling. Vertical turbulence intensity increases considerably near the wall as the velocity increases. The peak value of vertical turbulence intensity on immobile beds is less than 0.041 . The magnitude of the peak increases slightly to 0.045 during weak bedform movement (WM) and increases to 0.064 during strong mobile bedforms (SM1 and SM2). Increased turbulence is generated throughout the depth in mobile bedforms as compared to immobile beds and smooth bed (Roussinova et al. 2008) where the generation is dominant only in the near bed region. A significant shift in the profiles due to bed mobility is observed in Figs. 4(a) and 5(a). The differences between the streamwise and vertical turbulence intensities (Figs. $4 \mathrm{a}$ and $5 \mathrm{a}$ ) near the bed on the mobile bedforms provide evidence for high level of turbulence anisotropy, which penetrates deep into the flow.
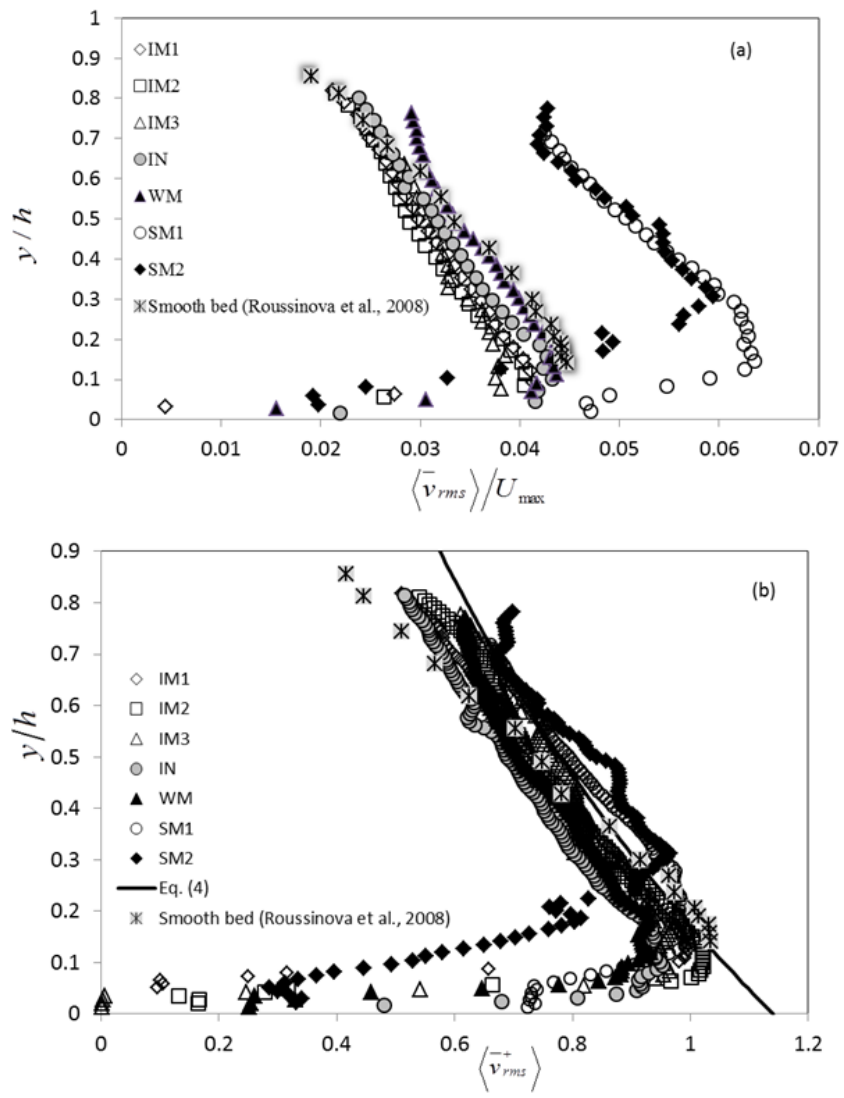

Fig. 5. Distributions of vertical turbulence intensity for all runs (a) normalized with maximum velocities, and (b) normalized with shear velocities. 
Fig. 5(b) shows the vertical distributions of $\left\langle\bar{v}_{r m s}\right\rangle^{+}$. The present results away from the wall are reasonably well described by the relationship developed for rough open channel flows by Song et al. (1994) and given by

$\bar{v}_{r m s}^{+}=1.14 \exp (-0.76 y / h)$

Mobile bedforms have slightly higher $\left\langle\bar{v}_{r m s}\right\rangle^{+}$distribution for $y / h>0.3$ as compared to the other cases. Ratios of $\bar{u}_{r m s} / \bar{v}_{r m s}$ in immobile rough beds for $0.1<y / h<0.8$ are found to be between 1.4 and 2.2, while higher values are obtained on the mobile bedforms ranging between 2.0 and 7.2. The values obtained from the empirical Eqs. (3) and (4) were also used to compute the anisotropy ratio $\bar{u}_{r m s} / \bar{v}_{r m s}$. The anisotropy ratio varies between 1.4 and 2.3 based on the empirical equations, which is in good agreement with present experimental data on immobile rough bed. It is observed that $\bar{u}_{r m s} / \bar{v}_{r m s}$ is very high in the mobile bedforms where an increase of the flow anisotropy is evident.

\section{Reynolds shear stress}

Figs. 6(a) and 6(b) show the Reynolds shear stress $-\left\langle\overline{u^{\prime} v^{\prime}}\right\rangle$ distribution in outer and inner scaling, respectively. The value of Reynolds stress increases with $y / h$ in the wall region, attains a maximum and then decreases towards the free surface in all experiments. The Reynolds shear stress increases with increasing flow rate as shown by the arrow. Fig. 6(a) also shows increased values of shear stress distribution throughout the depth in mobile bedforms. The smooth bed and fixed rough dune results are provided in Fig. 6(a) for qualitative comparison purposes. The Reynolds stress distributions of present experiments lie between the smooth bed (at $R_{e}=40244$ ) and fixed rough dune results $\left(R_{e}=51000\right)$. The distributions in SM1 and SM2 (Fig 5a and 6a) clearly show that Reynolds shear stresses over entire flow depth are affected by mobile bedforms as observed by Balachandar and Bhuiyan (2007) in flow over fixed rough dunes.

Fig. 6(b) shows the results using the boundary layer thickness $\delta$ as the length scale to maintain consistency with other results presented in boundary layer literature. Reynolds stress distributions in the present experiments conform to those available in the literature including the collapse onto the smooth wall results (Roussinova et al., 2008) in the region $y / \delta>0.3$. The shear stress attains a maximum near the wall region and decreases towards the free surface in IM, IN and WM and whereas shear stress reaches the peak values a little farther from the bed in SM1 and SM2. This behaviour is due to the viscous effects prevailing near the wall in smooth bed while in hydraulically rough flows it can be explained by the existence of a roughness sub-layer where additional mechanisms for momentum extraction exists (Nikora and Goring, 2000). The peak Reynolds stress of mobile bedforms (SM1 and SM2) occurs in the region $y / \delta>0.2$ whereas the peak occurs at $y / \delta<0.2$ in the immobile beds (IM1, IM2, IM3, IN and WM). An important observation in the present experimental studies is the damping of the $-\left\langle\overline{u^{\prime} v^{\prime}}\right\rangle^{+}$near the bed with increasing flow velocity. It is worth mentioning that the formation of the bedforms in the present experiments (tests SM1 and SM2) shows an increase of the streamwise velocity fluctuations. Near the bed, the magnitude of the Reynolds shear stress scaled with shear velocity on the mobile bedforms shown in Fig. 6(b) is less than that on the immobile beds contrary to the trend shown in Fig. 6(a) where Reynolds shear stress is normalized with maximum velocity. The apparent lower values of $-\left\langle\overline{u^{\prime} v^{\prime}}\right\rangle^{+}$near the bed in mobile
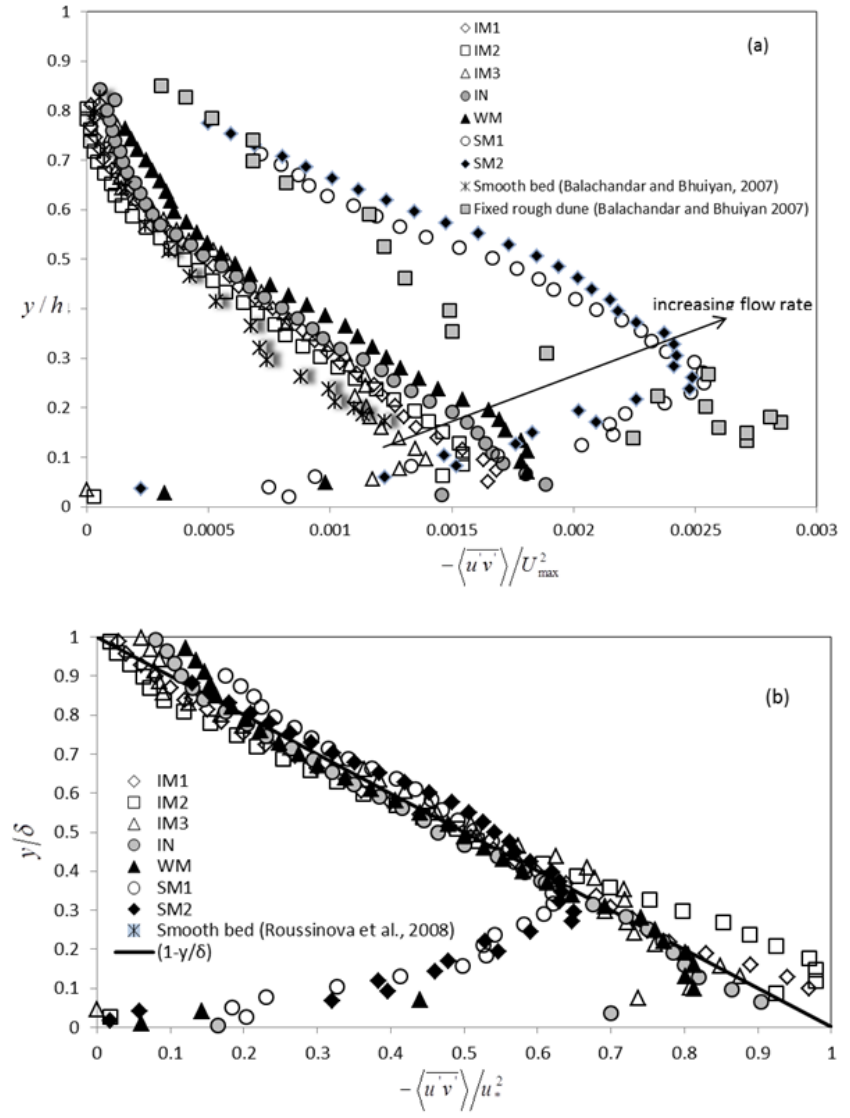

Fig. 6. Distribution of the Reynolds shear stress for all runs (a) as a function of $y / h$, normalized with maximum velocities, and (b) as a function of the $y / \delta$ and normalized with shear velocity.

bedforms as compared to immobile beds (refer to Fig. 6b) is attributed to scale effects. Morrison (2007) proposed that Reynolds stresses do not simply scale with kinematic viscosity and $u_{*}$ at high Reynolds number flows wherein large eddy motions penetrate to the wall causing increased effect of outer scale.

\section{Higher-order moments}

Higher order correlations contain important statistical information related to the flux and diffusion of the stresses developed due to turbulence and are directly attributable to the turbulent coherent structures. In addition, third order correlations preserve their signs either positive or negative, providing useful statistical information on the temporal distribution of velocity fluctuations with respect to the time averaged velocity. For instance $\overline{u^{\prime 2} v^{\prime}}$ defines the flux of Reynolds normal stress $\overline{u^{\prime 2}}$ driven by $v^{\prime}$. Similarly $\overline{u^{\prime} v^{\prime 2}}$ defines the flux of Reynolds normal stress $\overline{v^{\prime 2}}$ driven by $u^{\prime}$. The skewnesses $\overline{u^{\prime 3}}$ and $\overline{v^{\prime 3}}$ define the streamwise flux of the streamwise Reynolds normal stress $\overline{u^{\prime 2}}$ and vertical flux of the vertical Reynolds normal stress $\overline{v^{\prime 2}}$ respectively. Positive values of $\overline{v^{\prime 3}}$ and $\overline{u^{\prime 2} v^{\prime}}$ suggests fluxes of normal stresses $\overline{u^{\prime 2}}$ and $\overline{v^{\prime 2}}$ are upward direction which normally occurs for flows over rigid beds. Higher order moments $\overline{v^{\prime 3}}$ and $\overline{u^{\prime 2} v^{\prime}}$ being negative near the bed suggests fluxes of normal stresses $\overline{u^{\prime 2}}$ and $\overline{v^{\prime 2}}$ are acting over the bed in downward direction which suggest high bedload transport. Similarly negative values of $\overline{u^{\prime 3}}$ and $\overline{u^{\prime} v^{\prime 2}}$ imply that $\overline{u^{\prime 2}}$ and $\overline{v^{\prime 2}}$ transported against the streamwise direction caused by inertia of the 
flowing fluid. The positive values of $\overline{u^{\prime 3}}$ and $\overline{u^{\prime} v^{\prime 2}}$ imply $\overline{u^{\prime 2}}$ and $\overline{v^{\prime 2}}$ are transported in the streamwise direction which has accelerating effect on the flow with a profound effect on the suspended sediment. Together the negative values of $\overline{u^{\prime 3}}$ and $\overline{u^{\prime} v^{\prime 2}}$ and positive values of $\overline{v^{\prime 3}}$ and $\overline{u^{\prime 2} v^{\prime}}$ compose a retardation process with the arrival of slowly moving fluid parcel into flow region away from the bed which is also termed as ejection event. Similarly positive values of $\overline{u^{\prime 3}}$ and $\overline{u^{\prime} v^{\prime 2}}$ and negative values of $\overline{v^{\prime 3}}$ and $\overline{u^{\prime 2} v^{\prime}}$ indicate downward movement of high speed fluid parcel towards the bed which termed as sweep. The sweep events are mainly responsible for erosion and deposition of sediment.

Higher-order velocity moments are analysed in this paper to further describe the flow field on mobile bedforms. Figs. 7 and 8 show variation of velocity skewness factors $S_{u}$ and $S_{v}$ in streamwise and wall normal directions with $U_{\max }$ as the scaling variable $\left.\left(S_{u}=\left\langle\overline{u^{\prime 3}}\right\rangle / U_{\text {max }}^{3}\right), S_{v}=\left\langle\overline{v^{\prime 3}}\right\rangle / U_{\text {max }}^{3}\right)$. Near the bed, $S_{u}$ is positive for all flow conditions while in the outer layer, the magnitude of $S_{u}$ decreases with increasing $y$. The present immobile bed experiments compare well with the results of the LDV experiments of Faruque and Balachandar (2011) performed at a similar Reynolds number (Fig. 7a) but using different bed particle size. For WM and IN tests, the distribution of $S_{u}$ is positive near the bed and becomes negative at about $y / h=0.03$ as shown in Fig. 7(b). The global minimum of $S_{u}$ occurs at $y / h=0.06$ and then asymptotically approaches zero at $y=0.1 \mathrm{~h}$. In the case of the mobile bedform (SM1 and SM2), $S_{u}$ is significantly different in shape, magnitude and slope compared to that found on immobile beds. The point of the crossover (vertical location) where $S_{u}$ becomes equal to zero, is also different from that observed on the immobile bed experiments. The higher values of $S_{u}$ on the mobile bedforms are due to higher turbulence caused by the moving particles. Present results confirm the conclusion of Nezu and Nakagawa (1993) that strong turbulence activity near the bed results in an increase of $k_{s}^{+}$. Third-order moments of the velocity fluctuations $\overline{\left\langle u^{\prime 3}\right\rangle}$ normalized by friction velocity $S_{u}^{*}=\left\langle\overline{u^{\prime 3}}\right\rangle / u_{*}^{3}$ for immobile and mobile bedforms are shown in Figs. $7(\mathrm{c})$ and 7(d). It is observed from Fig. 7(c) that $\left\langle\overline{u^{\prime 3}}\right\rangle^{+}$variations of immobile beds (IM1, IM2 and IM3) lie between smooth bed and fixed rough dune. Clearly, roughness has a significant effect on the skewness distribution, i.e., skewness increases with increasing roughness. It appears that the skewness and turbulence anisotropy is higher in the case of flow over the fixed rough dune as compared to flow over present immobile rough beds (Nezu and Nakawaga, 1993). The $\left\langle\overline{u^{\prime 3}}\right\rangle^{+}$distribution attains a local maximum negative value in the logarithmic region $(y / h=0.07)$ for flows over smooth and immobile rough beds. The occurrence of negative values of $\left\langle\overline{u^{\prime 3}}\right\rangle^{+}$through most of the depth is consistent with the earlier observations. In the outer layer $(y / h>0.6)$, the values of $\left\langle\overline{u^{\prime 3}}\right\rangle^{+}$reduces rapidly. In Fig. $7(\mathrm{~d})$, distribution of $\left\langle\overline{\left\langle u^{\prime 3}\right.}\right\rangle^{+}$ during weak bedform movement (WM) is similar to that of incipient motion. However, the magnitude of the global minimum is more than that of incipient motion. For the mobile bedforms, the $\left\langle\overline{u^{\prime 3}}\right\rangle^{+}$distribution is positive near the bed,
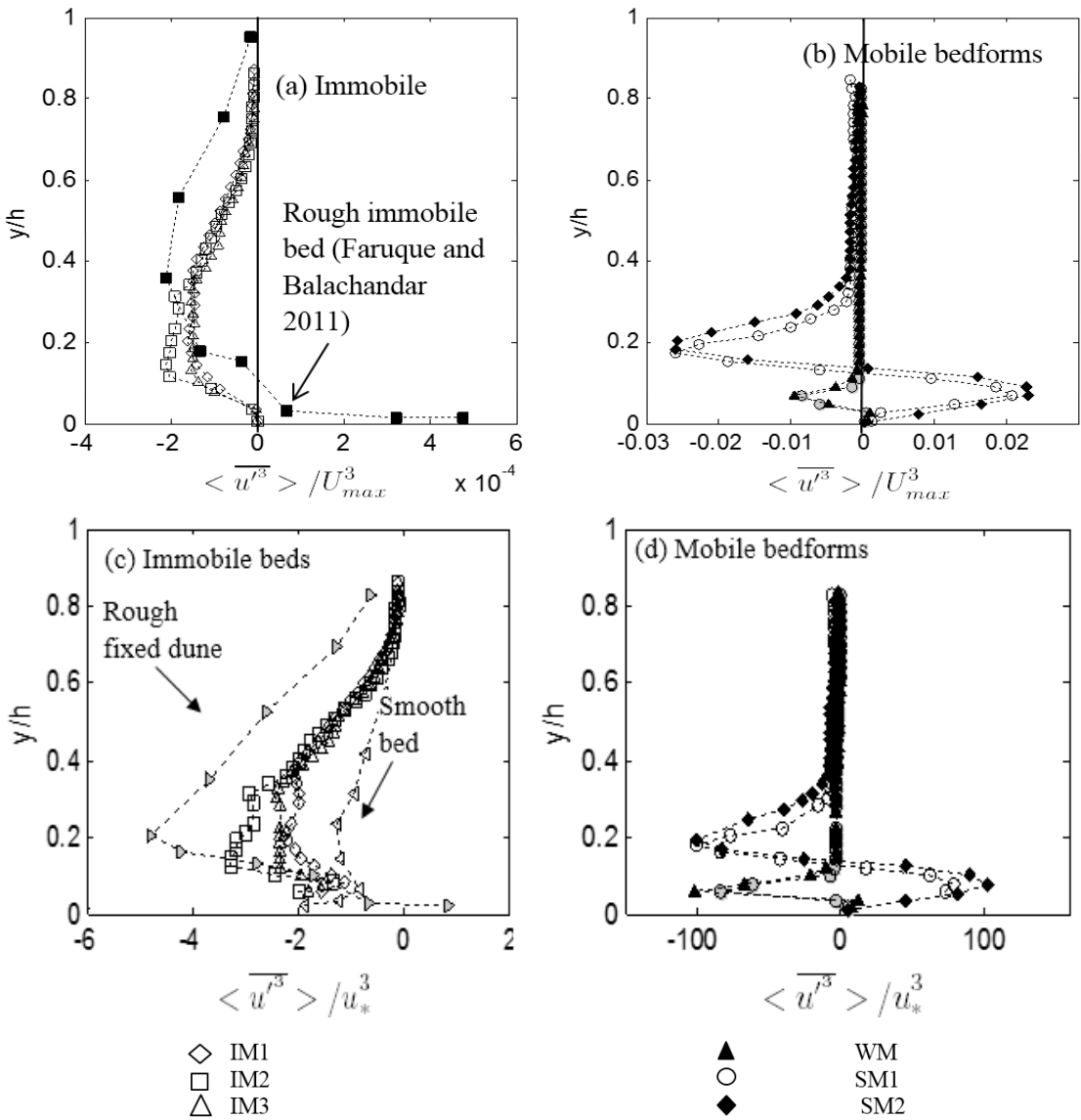

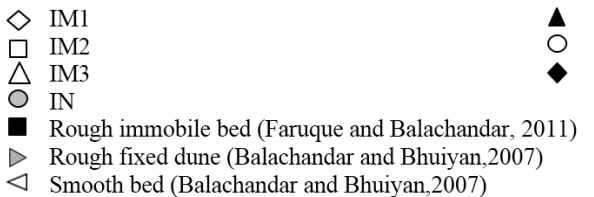

Fig. 7. Distribution of streamwise skewness factors $\left(S_{u}\right)$. 
attaining a positive peak away from the bed at $y \cong 0.1 \mathrm{~h}$. With further increase ofy, $\left\langle\overline{u^{\prime 3}}\right\rangle^{+}$distributions of SM1 and SM2 become negative and attain a negative peak at $y=0.18 \mathrm{~h}$. The magnitude of this peak is 20 times higher than that observed on the fixed rough dune. For $y>0.3 h$, the $\left\langle\overline{u^{\prime 3}}\right\rangle^{+}$distributions of mobile bedforms become very small and asymptotically approach zero.

The asymmetry and the higher magnitude of $\left\langle\overline{u^{\prime 3}}\right\rangle^{+}$obtained near the bed $(y<0.3 h)$ on mobile bedforms and during the incipient motion indicate the prevalence of high turbulence activity due to the moving bed particles.

The normalized third-order moments of the wall normal velocity fluctuations are shown in Fig. 8. Unlike the $S_{u}$ distribution, the magnitudes of the peaks of $S_{v}$ distribution of the mobile bedforms are comparable to immobile beds. The profiles of $S_{v}$ of immobile beds fall between smooth and rough fixed dune beds. Distributions of $S_{v}$ are found to be positive throughout the depth in immobile beds for all flow conditions (Figs. 8a and 8c) which is in line with smooth bed and fixed rough dune bed data of Balachandar and Bhuiyan (2007). The variation of $S_{v}$ in the flow over mobile bedforms is quite different from that of immobile beds (Figs. 8b and 8d). In IN and WM, positive values of $S_{v}$, throughout the depth, imply downward transport of the turbulent kinetic energy for $y / h<$ 0.1. Comparison of the results of SM1 and SM2 (Figs. 8b and 8d) show an increase in negative peak with the increase in flow velocity. This implies that vertical turbulent kinetic energy is acting downwards near the bed $(y<0.14 h$ in SM1 and $y<0.24 h$ in SM2) and upwards in the outer layer in both mobile bedforms experiments. Several researchers reported that the vertical kinetic energy acts downwards near the bed in mobile beds. Regions of downward flow and influence of wall region is increased from SM1 to SM2 due to increase in bed roughness as well as bed movement. However, the effect of bed roughness is diminished away from the wall (for $y>$ $0.14 h$ in SM1 and $y>0.24 h$ in SM2). The $S_{v}$ distributions on mobile bedforms (SM1 and SM2) decrease for $y>0.6 h$ (outer layer) while $S_{v}$ distributions on immobile bed and fixed rough dune (Balachandar and Bhuiyan, 2007) decrease at $y=0.37 h$ as shown in the figures. This indicates the extension of the zone of turbulent energy generation and hydrodynamic roughness farther away from the bed where upward flow is pushed in the outer layer during sediment transport. Peak values of $S_{v}$ distribution in mobile bedforms occur farther away from the bed (Fig. 8b) which shows significant turbulent energy enhancement at $y / h>0.70$. In Fig. 9, turbulent diffusion coefficients $D_{u *}=\left\langle\overline{u^{\prime} v^{\prime 2}}\right\rangle^{+}$and $D_{v^{*}}=\left\langle\overline{\left\langle u^{\prime 2} v^{\prime}\right.}\right\rangle^{+}$are presented. In Fig. 9(a), $D_{u *}$ remains negative and decreases with increasing distance from the bed, attaining a negative peak at $y \cong 0.2 h$. In the outer layer, $D_{u *}$ approaches zero for the immobile bed tests and the fixed rough dunes (Balachandar and Bhuiyan, 2007). This indicates streamwise deceleration of the flow associated with an outward momentum transfer near the bed. During incipient motion and weak bed
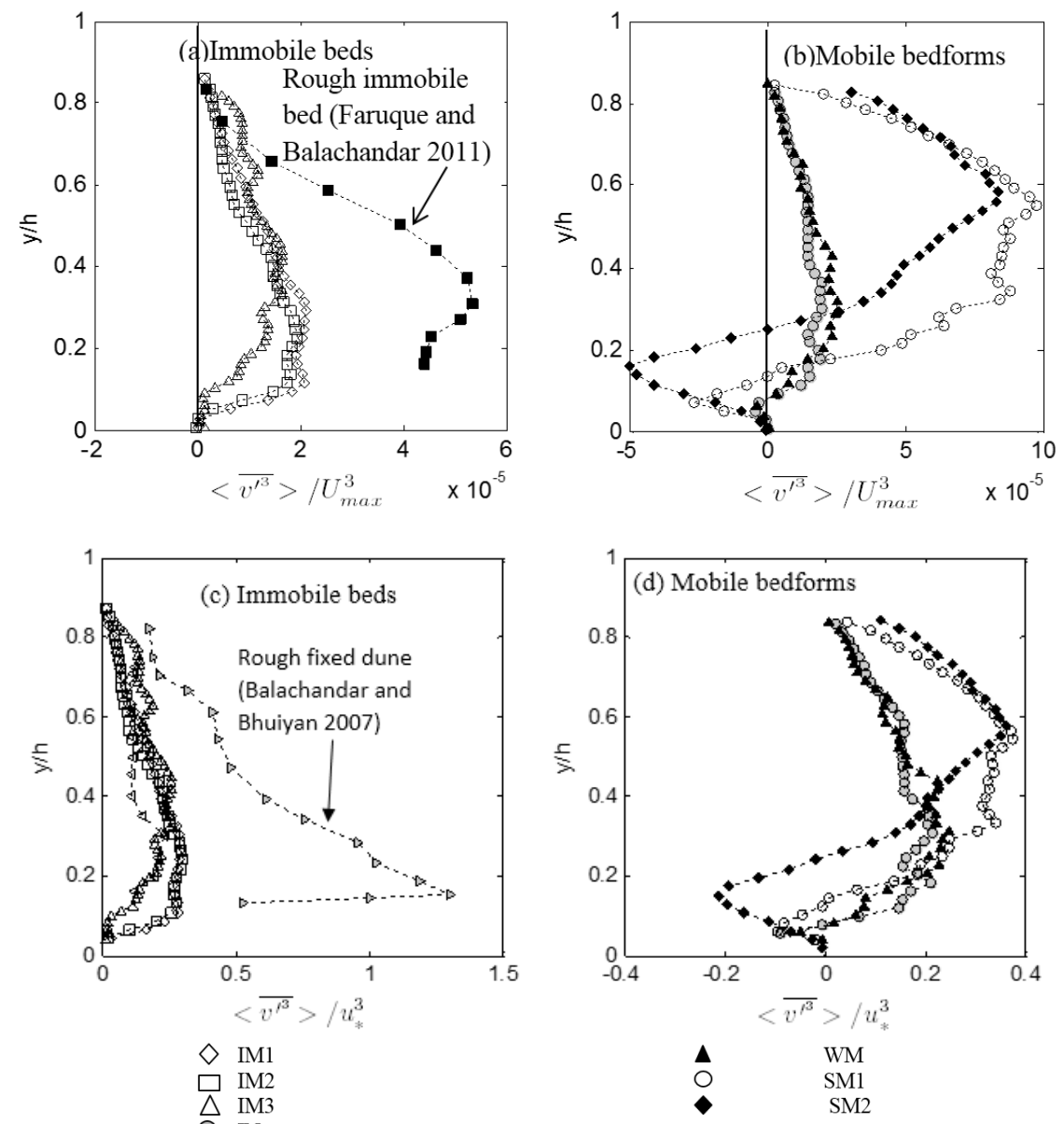

$\diamond \mathrm{IM} 1$

$\square$ IM2

$\triangle \mathrm{IM} 3$

O IN

Rough immobile bed (Faruque and Balachandar, 2011)

Rough fixed dune (Balachandar and Bhuiyan, 2007)

$\checkmark$ Smooth bed (Balachandar and Bhuivan, 2007)

Fig. 8. Distribution of vertical skewness factors $\left(S_{v}\right)$. 
movement (IN and WM), $D_{u *}$ has a higher positive value near the bed and it is similar to immobile beds at $y / h>0.09$ (Fig. $9 \mathrm{~b})$. In mobile bedforms, $D_{u *}$ increases with distance from the bed, attains a maximum positive value and decrease in the region $0.1<y / h<0.24$. For $y / h>0.24, D_{u *}$ is negative and approaches small negative values near the free surface. Near the bed, this indicates a streamwise acceleration associated with the downward momentum transfer. Conversely, a streamwise deceleration of flow associated with an upward momentum transfer is noticed outside the inner layer.

Distribution of $D_{v *}$ attains positive maximum value at $y=0.15 h$ and decreases towards zero with increasing $y$ in immobile beds as shown in Fig. 9 (c). The wall normal transport of streamwise turbulent kinetic energy decreases in the upward direction for $y>0.2 h$. In Fig. 9(c), the distributions of $D_{v *}$ of immobile beds are located between the smooth and fixed rough dune bed experiments of Balachandar and Bhuiyan (2007). In the immobile bed experiments the roughness is 3-D and it is expected to behave differently from the 2-Drough fixed dunes. The sediment motion plays an important role in transferring turbulence energy towards the wall. Distributions of $D_{v_{*}}$ (Figs. 9c, 9d) are similar to distribution of $D_{u *}$ (Figs. 9a, 9b) but with an opposite sign. Both diffusion factors are strongly affected by the bedform mobility and sediment transport. In the SM1 and SM2 tests, the positive peak of $D_{v_{*}}$ and the negative peak of $D_{u *}$ occur farther away from the bed in the outer region $(y / h=0.4)$ which indicates that the entire flow depth is affected and turbulent kinetic energy is transferred mostly in the upward direction (Fig. 9). Conversely, turbulence diffusion becomes negligible in the outer region for all immobile bed experiments.

The changeover of signs in the distributions occurs at the crest height of the dunes formed on the bed. The division of the flow zones with respect to the crest level and trough region and the bedforms induced roughness layer will cause the changeover of signs in the third- order moment distribution of mobile bedforms as shown in Figs.7(b, d), 8(b, d) and 9(b, d).

\section{Quadrant analysis}

To further quantify the differences in turbulence structure over the immobile bed and temporally varying mobile bedforms, a quadrant analysis was carried out to evaluate the shear stress production by the coherent structures and to detect extreme events in four quadrants in the $u^{\prime}$ and $v^{\prime}$ plane. At every measurement location, the Reynolds shear stress is calculated and further decomposed as a sum of different events according to the procedure given in Balachandar and Bhuiyan (2007). By using the concept of a hyperbolic hole of size $H$, defined by $\left|u^{\prime} v^{\prime}\right|=H u_{r m s} v_{r m s}$, the contribution from a particular quadrant can be written as

$$
\left(\overline{u^{\prime} v^{\prime}}\right)_{Q, H}=\lim _{T \rightarrow \infty} \frac{1}{N} \int_{0}^{N} u^{\prime}(t) v^{\prime}(t) \Phi_{Q}(t) d t
$$
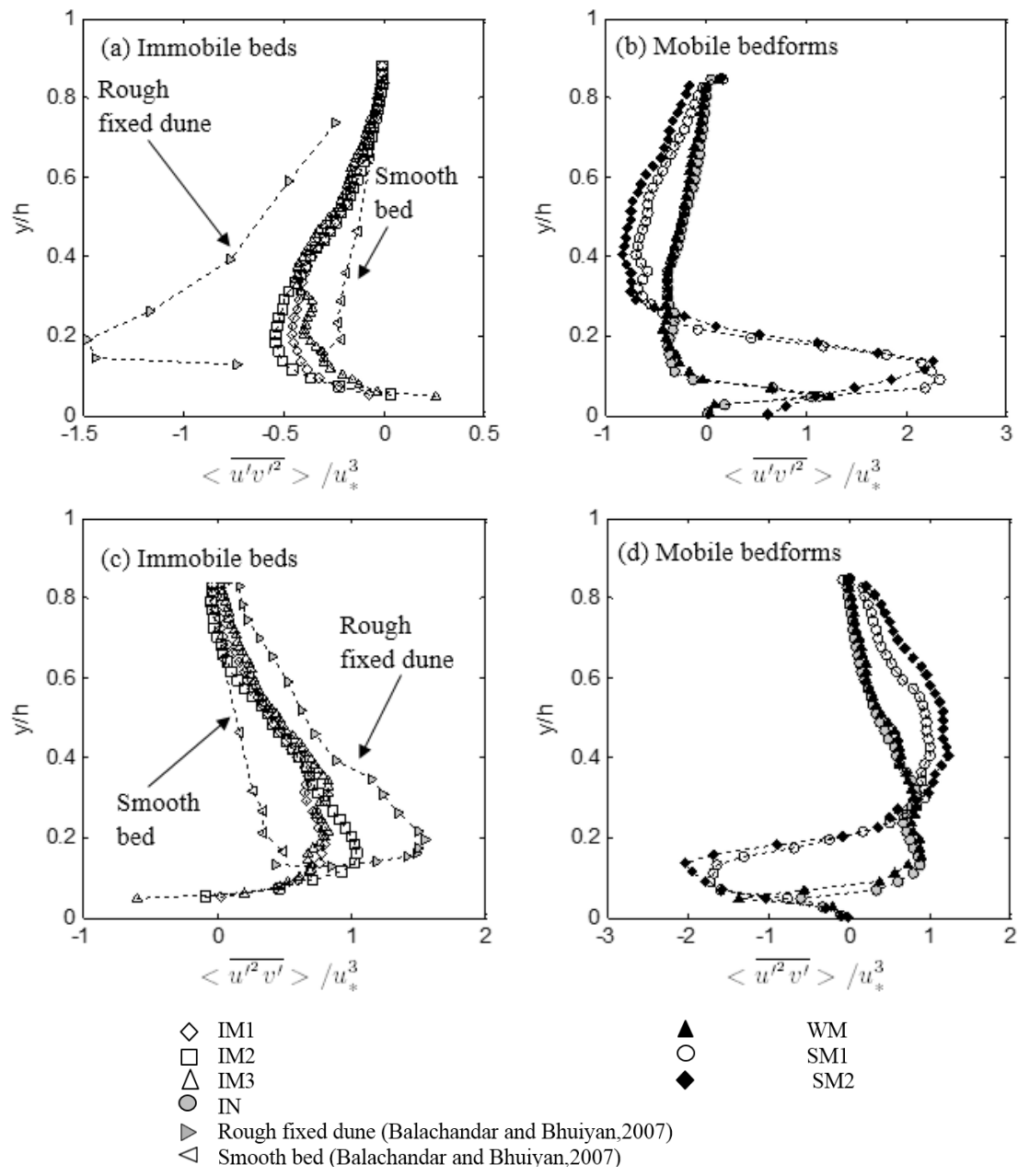

Fig. 9. (a, b) Streamwise and (c, d) vertical turbulent diffusion factors normalized by shear velocities in mobile bedforms, immobile rough beds, smooth bed and fixed rough dunes bed. 
Here $\Phi_{Q}(t)$ is a detection function defined as

$\Phi_{Q}(t)=\left\{\begin{array}{l}1, \text { when }\left|u^{\prime} v^{\prime}\right|_{Q} \geq H u_{r m s} v_{r m s} \\ 0, \text { otherwise }\end{array}\right.$

The parameter $H$ defines a threshold value, which separates the extreme events from the random background turbulence, $N$ is number of samples, $Q$ is a particular quadrant and $t$ is sampling instant. By increasing the value of $H$ more extreme/strong events are identified. Earlier, Nezu and Nakagawa (1993) have noticed the occurrence of dune-related bursting or ejections in experiments. Balachandar and Bhuiyan (2007) found that flow over fixed rough surfaces, $Q 2$ and $Q 4$ events make significant contributions to the shear stress closer to the bed. They also found that the ejection events are dominant throughout the depth and vary significantly with wall roughness.

To study the fractional contributions towards the Reynolds shear stresses production from different bursting events, the data of $S_{Q, H}$ equal to $\left(\overline{u^{\prime} v^{\prime}}\right)_{Q, H}$ normalized by localized Reynolds shear stress $\left(\overline{u^{\prime} v^{\prime}}\right)$ for $H=0$ and 2 are plotted in Figs. 10 and 11. The Reynolds shear stress fractional contribution $\left(S_{Q, H}\right)$ to each event is given by following equation.

$S_{Q, H}=\frac{\left(\overline{u^{\prime} v^{\prime}}\right)_{Q, H}}{\overline{u^{\prime} v^{\prime}}}$

For quadrant analysis, double averaging has not been carried out. The quadrant analysis presented in Figs 10 and 11 represents instantaneous velocities measured along the centerline of 2000 images, i.e., events only at the midsections of 2000 PIV images were considered to compute the contributions of Reynolds shear stresses in each quadrant. Along the centerline of the image, at every $y$ co-ordinate only 2000 instantaneous $u$ and $v$ velocities are available. However, quadrant analysis requires at least 5000 instantaneous velocities and more data is better. To increase the number of instantaneous velocities along the centerline, velocities measured immediate adjacent on both sides of mid vertical line of the image $[x($ mid $)-d x, y],[x($ mid $), y]$, $[x($ mid $)+d x, y]$ were also considered where centerline $x$ coordinate is represented by $x$ (mid) and $x$-coordinate of the two lines on the immediate both sides of the centerline are represented by $x($ mid $)-d x$ and $x($ mid $)+d x$ respectively. Here $d x$ value is a fraction of millimeter. Therefore at each and every $y$-ccoordinate 6000 instantaneous velocities were made available for the quadrant analysis.

Only the immobile bed (IM1), weakly mobile bedforms (WM) and strongly mobile bedforms (SM2) are presented in this section. It is observed from Figs. 10 and 11 that ejection events $(Q 2)$ and inward events $(Q 3)$ in the inner region are stronger in immobile bed and their order is IM1 $>\mathrm{WM}>\mathrm{SM} 2$. However, ejection events $(Q 2)$ and inward events $(Q 3)$ are stronger in the outer region in strongly mobile bedforms and their strength is in the order of SM2 $>$ WM $>$ IM1. Figs. 10 and 11 demonstrate that outward $(Q 1)$ and sweep events $(Q 4)$ are strong near the bed in mobile bedforms. Comparatively the strength of sweep events $(Q 4)$ near the bed is greater than ejection events $(Q 2)$ in mobile bedforms. The analysis emphasizes that bedforms mobility is governed by the strength and number of sweep $(Q 4)$ events which shows that sweep events are predominant in mobile beds. Sweep events are dominant on the mobile bedforms due to flow separation on lee side and followed by flow reattachment on the stoss slope of the dune.
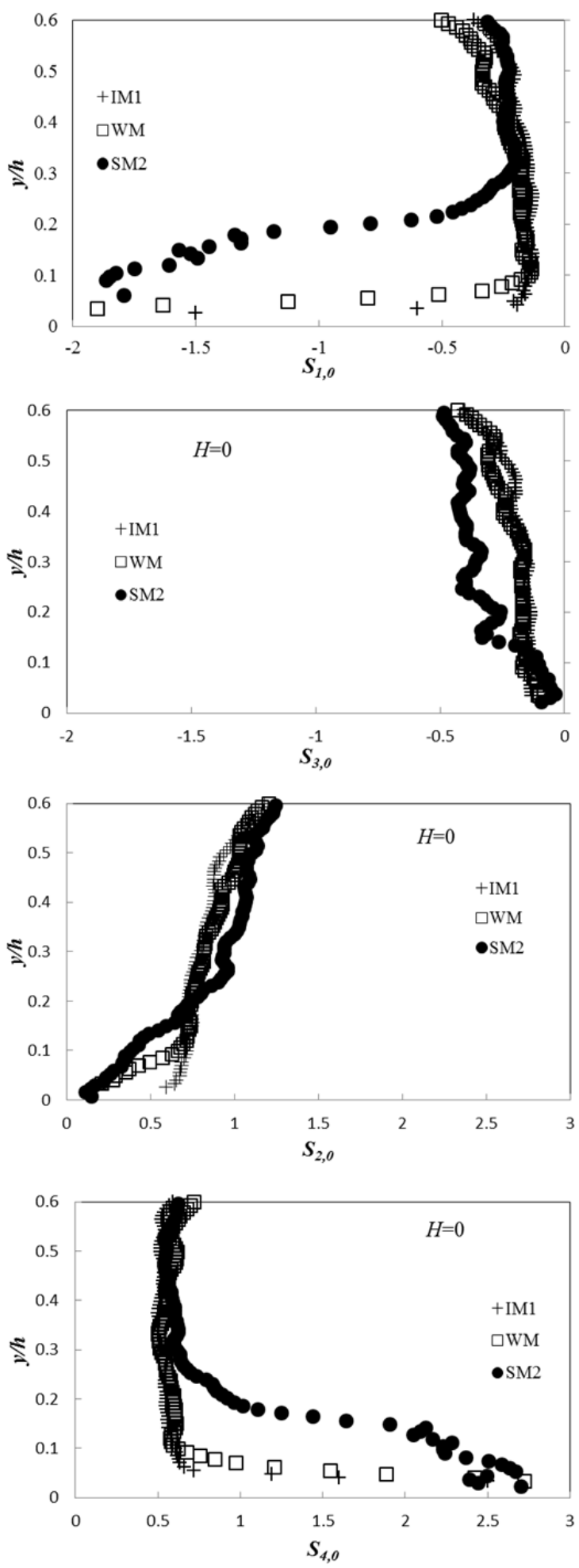

Fig. 10. Depth variation of quadrant events for immobile, weakly mobile and strongly mobile bedforms $(H=0)$.

Visual analysis of the PIV images in SM2 experiment shown that dune moved 10 times across the PIV field-of-view during the total duration of the experiment. In one of the dune crossings, the instantaneous velocities were analysed. The fluctuating velocities were computed as the dune progresses across the PIV field-of-view, localization and percentages of instantaneous inward, ejection, outward and sweep events are presented in Fig. 12. The time lags between the images 12(a) and 12(b), $12(\mathrm{~b})$ and 12(c), and 12(c) and 12(d) are $8 \mathrm{~s}, 12 \mathrm{~s}$, and $10 \mathrm{~s}$, 

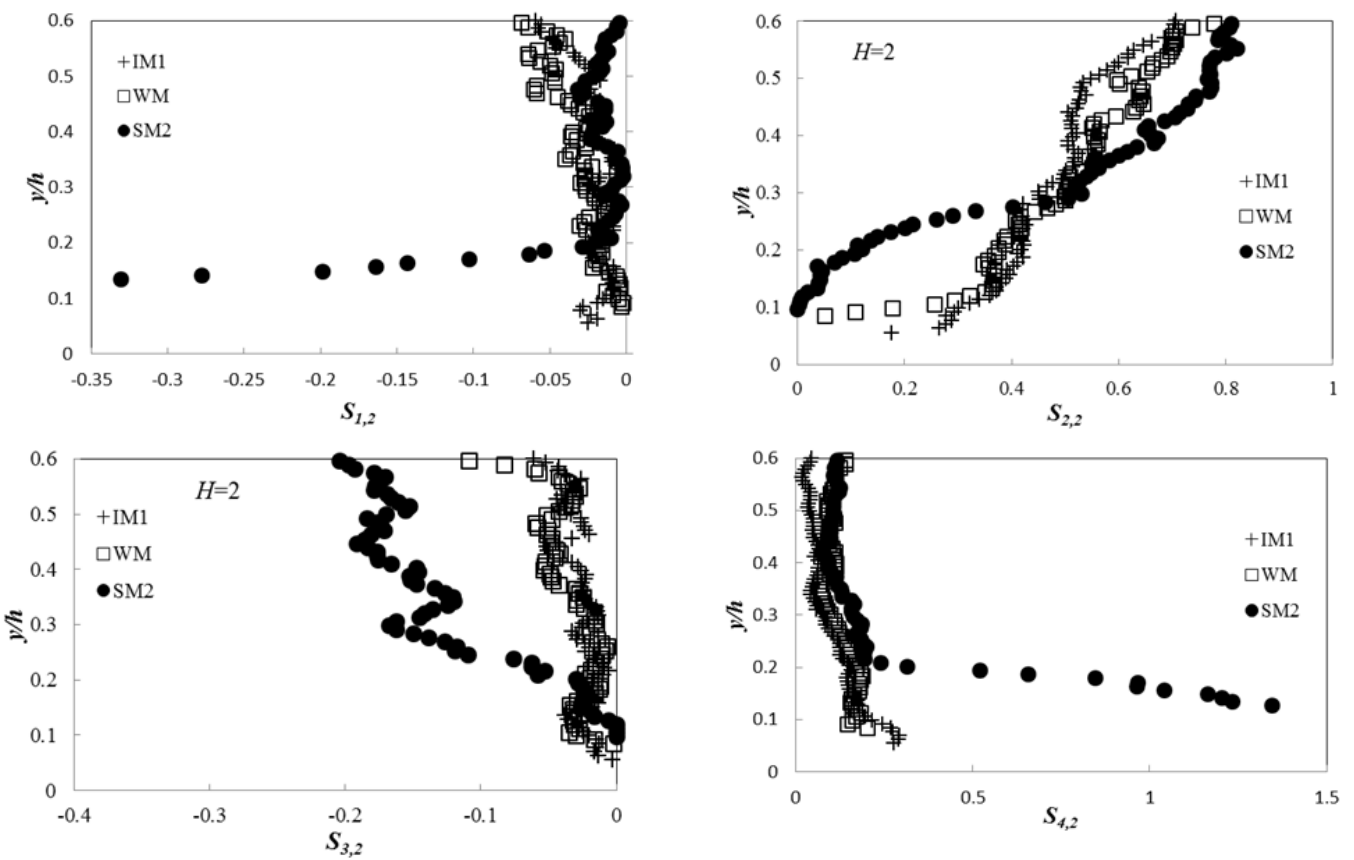

Fig. 11. Depth variation of quadrant events for immobile, weakly mobile and strongly mobile bedforms $(H=2)$.

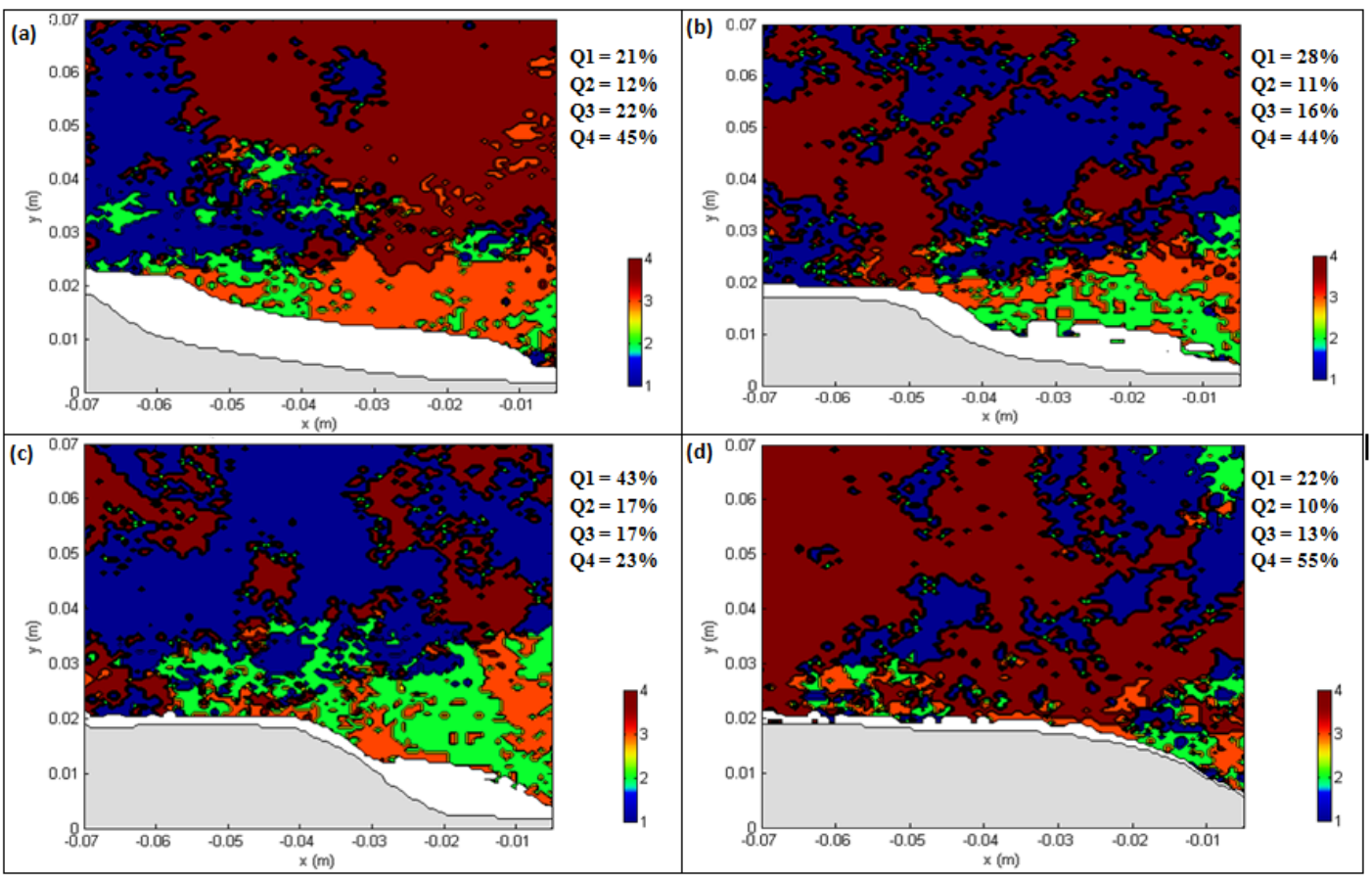

Fig. 12. Fluctuating velocity quadrants as the mobile dune moves across PIV window in SM2 experiment, dune (a) at beginning of PIV window, (b) crossed 1/3 of PIV window, and (c) crossed 2/3 of PIV window, and (d) at end of PIV window.

respectively. The dune crossed the PIV field-of-view in approximately 20 images at a speed of $1.8 \mathrm{~mm} / \mathrm{s}$. In each of these images (Fig. 12), dune as well as light reflection (white colour in Fig. 12) on the surface of the dune were removed (masked) for further analysis. Fluctuating velocities $\left(u^{\prime}\right.$ and $\left.v^{\prime}\right)$ were available at each interrogation window in the cleaned image. Depending on positive and negative signs of fluctuating velocities, events were divided into four quadrants (outward events $(Q 1)$, ejection events $(Q 2)$, inward events $(Q 3)$ and sweep events $(Q 4))$. Percentages of each type of events were calculated and displayed on Fig. 12. From the figure, it can be inferred that the number of $Q 1$ and $Q 4$ events are dominant in the flow over mobile bedforms as compared to the number of $Q 2$ and $Q 3$ events. It is observed that the average number of $Q 4$ events is $42 \%$, and the number of $Q 1$ events is $30 \%$ and the remaining $28 \%$ are composed of $Q 2$ and $Q 3$ events. Therefore the analysis of instantaneous images of mobile bedform proves that outward and sweep events cause sediment entrainment and contribute to the movement of non-equilibrium bedforms more than ejections and inward events. Being number of $Q 1$ events exceeding $Q 2$ events reveal that rolling is the dominant mode of sediment entrainment as compared to lifting of sediment particles in non-equilibrium mobile bedforms which was also visually observed in our experiments. 
Turbulence characteristics of flow in an open channel with temporally varying mobile bedforms

\section{CONCLUSIONS}

The objective of this paper was to study the turbulence characteristics of open channel flow under immobile bed and nonequilibrium mobile bedforms conditions using the PIV technique. The double averaged mean velocity profiles were found to decrease in the vicinity of the bed during incipient and mobile bedforms (sediment transport) conditions. This was attributed to the fluidised conditions arising when the bed particles become mobile. Flow momentum was continuously extracted from the mean flow to accelerate the bed particles, which ultimately resulted in increasing bed resistance for the mobile bedforms conditions. It is worth to note that the transient effect of the bedforms (such as dunes) was also a contributing factor to the overall increase of the bed resistance. Velocity profiles of the present mobile bedforms experiments conform to the classical log-law of the wall with an increasing velocity shift due to increasing roughness and reduced von Kármán constant. This study confirmed the conclusions from previous experimental and numerical studies on the non-universality of the von Kármán constant in the case of the fluvial mobile bed.

Streamwise and vertical turbulence intensities on the mobile bedforms are much higher than those observed on the immobile beds. The effect of the mobile bedforms roughness is felt throughout the entire flow depth, compared to a small region near the bed as observed in immobile beds. The anisotropy ratio $u_{r m s}^{+} / v_{r m s}^{+}$was also higher in the case of mobile bedforms. The peak of the Reynolds stress in outer variables is occurring farther away from the wall in mobile bedforms, whereas the peak of the Reynolds stress of immobile beds is occurring near the wall. The Reynolds shear stress distributions in outer variables show a drastic increase in mobile bedforms. It is concluded that the amount of shear stress increment and the affected region of flow depth due to the increase in Reynolds number was higher in mobile bedforms than the shear stress variation observed in the immobile beds. It is further concluded that bed roughness effects in mobile bedforms are not limited only to the wall region, but extends close to the free surface and as compared to the mobility of the dunes, the dunes size and shape have a greater effect on the turbulence structure along the depth. Peak value of non-dimensional Reynolds shear stress (normalized with shear velocity) is decreasing with increasing Reynolds number of the flow, demonstrating that the use of inner scaling for mobile bedforms is inappropriate.

The higher-order moments (skewness and turbulent diffusion factors) on mobile bedforms are different to those of immobile rough bed, fixed smooth and fixed rough dune beds. An interesting observation in the present experiments is that the computed skewness factors in mobile bedforms are approximately two orders of magnitude higher than those of immobile beds for an approximately similar Reynolds number. The higher magnitude of $S_{u}$ and $S_{v}$ indicates the existence of significant turbulent activity and intermittency of turbulent events throughout the depth. The turbulence diffusion factors are found to be significantly affected by the bed mobility and the formation of bedforms. The increase of the turbulence diffusion during the mobile bedform experiments indicates streamwise acceleration of the flow associated with an increase of the downward momentum transfer near the bed.

From the quadrant analysis of midsection of PIV field-ofview, it was observed that ejection events $(Q 2)$ and inward events $(Q 3)$ in the inner region in the immobile bed case are stronger than in the weakly mobile bedforms case. Ejection events $(Q 2)$ and inward events $(Q 3)$ are weak near the bed in strongly mobile bedforms. However, ejection events $(Q 2)$ and inward events $(Q 3)$ in outer region in strongly mobile bedforms are stronger than in the weakly mobile bedforms and immobile beds. Outward $(Q 1)$ and sweep events $(Q 4)$ are strongest near the bed in strongly mobile bedforms. Comparatively the strength of sweep events $(Q 4)$ near the bed is greater than ejection events $(Q 2)$ in strongly mobile bedforms. The quadrant analysis in present study emphasizes that bedform mobility is governed by the strength and frequency of the sweep (Q4) events.

The analysis of instantaneous images of mobile bedform for fluctuating velocities in four quadrants demonstrated that the frequency of $Q 1$ and $Q 4$ events is more dominant than of $Q 2$ and $Q 3$ events in flow over strongly mobile bedforms. It is observed in flow over strongly mobile bedforms that the number of $Q 4$ events is $42 \%$, the number of $Q 1$ events is $30 \%$ and remaining 28\% are equally composed of $Q 2$ and $Q 3$ events. Present study of instantaneous images of mobile bedform indicates that outward and sweep events cause sediment entrainment and contribute to movement of non-equilibrium bedforms more than ejections and inward events. Number of $Q 1$ events exceeding $Q 2$ events reveals that rolling is dominant mode of sediment entrainment as compared to lifting of sediment particles in non-equilibrium mobile bedforms which was also visually observed in our experiments.

The results presented in this paper are important for understanding turbulence over mobile bedforms in natural rivers. The present experiments provide a quantitative evaluation of mobile bedforms on frictional characteristics of the flow. In addition, it is found that flow over mobile bedforms is in the hydraulically rough regime in which roughness effects the flow velocity throughout the depth. Outer scaling appears to be best for such kind of flows.

\section{REFERENCES}

Andreas, E., Claffey, K., Jordan, R., Fairall, C.W., Guest, P.S., Persson, P.L.G., Grachev, A.A., 2006. Evaluations of the von Kármán constant in the atmospheric surface layer. J. Fluid Mech., 559, 117-149.

Balachandar, R., Bhuiyan, F., 2007. Higher-order moments of velocity fluctuations in an open channel flow with large bottom roughness. J. Hydraul. Eng., 133, 77-87.

Balachandar, R., Patel, V.C., 2002. Rough wall boundary layer on plates in open channels. J. Hydraul. Eng., 128, 10, 947-951.

Balachandar, R., Patel, V.C., 2008. Flow over a fixed rough dune. Can. J. Civil Eng., 35, 511-520.

Balachandar, R., Blakely, D., Tachie, M.F., Putz, G., 2001. A study of turbulent boundary layer on a smooth flat plate in an open channel. J. Fluids Eng., 123, 2, 394-400.

Bennett, S.J., Bridge, J.S., Best, J.L., 1998. Fluid and sediment dynamics of upper stage plane beds. J. Geophys. Res., 103, C1, 1239-1274.

Bigillon, F., Niño, Y., Garcia, M.H., 2006. Measurements of turbulence characteristics in an open-channel flow over a transitionally-rough bed using particle image velocimetry. Exp. Fluids, 41, 6, 857-867.

Faruque, A.A., Balachandar, R., 2011. Seepage effects on turbulence characteristics in an open channel flow. Can. J. Civil Eng., 38, 7, 785-799.

Gupta, A.D., Paudyal, G.N., 1985. Characteristics of free surface flow over a gravel bed. J. Irrig. Drain. E. ASCE, 111, 4, 229-318.

Gyr, A., Schmid, A., 1997. Turbulent flows over smooth erodible sand beds in flumes. J. Hydr. Res., 35, 4, 525-544. 
Keirsbulck, L., Mazouz, A., Labraga, L., Tournier, C., 2001. Influence of the surface roughness on the third-order moments of velocity fluctuations. Exp. Fluids, 30, 592-594.

Keylock, C.J., Singh, A.L., Foufoula-Georgiou, E., 2013. The influence of migrating bedforms on the velocityintermittency structure of turbulent flow over a gravel bed. Geophys. Res. Lett., 40, 7, 1351-1355.

Kirkgöz, M.S., Ardichoğlu, M., 1997. Velocity profiles of developing and developed open channel flow. J. Hydraul. Eng. ASCE, 123, 12, 1099-1105.

Krogstad, P., Antonia, R., Browne, L., 1992. Comparison between rough-and-smooth-wall turbulent boundary layers. J. Fluid Mech., 245, 599-617.

Morrison, J.F., 2007. The interaction between inner and outer regions of turbulent wall-bounded flow. Phil. Trans. R. Soc. A, 365, 683-698. DOI: 10.1098/rsta.2006.1947.

Nelson, J.M., Logan, B.L., Kinzel, P.J., Shimizu, Y., Giri, S., Shreve R.L., McLean, S.R., 2011. Bedform response to flow variability. Earth Surf. Process. Landforms, 36, 14, 1938-1947.

Nezu, I., 2005. Open channel flow turbulence and its research prospect in the 21st century. J. Hydraul. Eng. ASCE, 131, 4, 229-246.

Nezu, I., Nakagawa, H., 1993. Turbulence in Open Channel Flows. IAHR Monograph, Balkema, Rotterdam.

Nikora, V., Goring, D., 2000. Flow turbulence over fixed and weakly mobile gravel beds. J. Hydraul. Eng., 126, 9, 679-690.

Nikora, V.I., McEwan, I.K., McLean, S.R., Coleman, S.E., Pokrajac, D., Walters, R., 2007a. Double-averaging concept for rough-bed open-channel and overland flows: Theoretical background. J. Hydraul. Eng., 133, 8, 873-883.

Nikora, V.I., McEwan, I.K., McLean, S.R., Coleman, S.E., Pokrajac, D., Walters, R., 2007b. Double-averaging concept for rough-bed open-channel and overland flows: applications. J. Hydraul. Eng., 133, 8, 884-895.

Raupach, M.R., Antonia, R.A., Rajagopalan, S., 1991. Rough wall turbulent boundary layers. Appl. Mech. Rev., 44, 1-25.

Robert, A., Uhlman, W., 2001. An experimental study of the ripple-dune transition. Earth Surf. Process. Landforms, 26, 6, 615-629.

Roussinova, V., Biswas, N., Balachandar, R., 2008. Revisiting turbulence in smooth uniform open channel flow. J. Hydraul. Res., 46, Suppl. 1, 36-48.

Roussinova, V., Shinneeb, A.M., Balachandar, R., 2010. Investigation of fluid structures in a smooth open-channel flow using proper orthogonal decomposition. J. Hydraul. Eng., 136, 3, 143-154.

Schindler, R.J., Robert, A., 2005. Flow and turbulence structure across the ripple-dune transition: An experiment under mobile bed conditions. Sedimentology, 52, 3, 627-649.

Shinneeb, A.-M., Bugg, J.D., Balachandar, R., 2004. Variable threshold outlier identification in PIV data. Meas. Sci. Technol., 15, 9, 1722-1732.

Song, T., Graf, W.H., Lemmin, U., 1994. Uniform flow in open channels with movable gravel bed. J. Hydraul. Res., 32, 6, 861-876.

Singh, A., Porté-Agel, F., Foufoula-Georgiou E., 2010. On the influence of gravel bed dynamics on velocity power spectra. Water Resour. Res., 46, 4, W04509. DOI: 10.1029/2009WR008190.

Tachie, M.F., Bergstrom, D.J., Balachandar, R., 2000. Rough wall turbulent boundary layers in shallow open channel flow. J. Fluids Eng., 122, 3, 533-541.

Tachie, M.F., Bergstrom, D.J., Balachandar, R., 2004. Roughness effects on the mixing properties in open-channel turbulent boundary layers. J. Fluids Eng., 126, 6, 1025-1032.

\section{NOMENCLATURE}

$B \quad$ constant in the log-law $=5.0(-)$

$\varepsilon \quad$ shift in the virtual origin (m)

$d_{50} \quad$ median size of sand particles $(\mathrm{m})$

$\delta \quad$ boundary layer thickness (m)

$\Delta \quad$ displacement height (m)

$h \quad$ water depth (m)

$H \quad$ threshold hole size $(-)$

$k_{s} \quad$ roughness height (m)

$k_{S}^{+} \quad$ roughness Reynolds number (-)

$\kappa \quad$ von Kármán constant $(-)$

$N \quad$ number of samples (-)

$\Pi \quad$ the wake parameter $(-)$

$Q \quad$ particular quadrant (-)

$R_{e} \quad$ flow Reynolds number $R_{e}=U_{\max } h / v(-)$

$R_{x} \quad$ Reynolds number based on the streamwise distance of measurement section $R_{x}=u_{*} x / v$

$t \quad$ sampling instant (s)

$\tau_{o c} \quad$ critical shear stress $\left(\mathrm{N} / \mathrm{m}^{2}\right)$

$\tau_{o} \quad$ bed shear stress $\left(\mathrm{N} / \mathrm{m}^{2}\right)$

$\Delta U^{+} \quad$ downward shift in the log-law due to roughness (-)

$U$ mean velocity at an elevation $y$ above the reference bed $(\mathrm{m} / \mathrm{s})$

$u^{\prime}, v^{\prime}$ streamwise and wall normal velocity fluctuations respectively $(\mathrm{m} / \mathrm{s})$

$U_{\max }$ maximum mean flow velocity $(\mathrm{m} / \mathrm{s})$

$u_{*} \quad$ friction velocity $\left(\mathrm{m}^{2} / \mathrm{s}\right)$

$v \quad$ kinematic viscosity of water at $15^{\circ} \mathrm{C}=1.15 \times 10^{-6} \mathrm{~m}^{2} / \mathrm{s}$

$y \quad$ wall normal distance above the reference bed (m)

$y_{o}$ the surface roughness (m)

$y^{+} \quad$ non-dimensional wall normal axis $(-)$

$\bar{u}_{r m s}, \bar{v}_{r m s}$ streamwise and wall normal turbulent intensities $(\mathrm{m} / \mathrm{s})$

$\left\langle\bar{u}_{r m s}\right\rangle,\left\langle\bar{v}_{r m s}\right\rangle$ double averaged streamwise and wall normal turbulent intensities $(\mathrm{m} / \mathrm{s})$

$\bar{u}_{r m s}^{+}, \bar{v}_{r m s}^{+}$streamwise and wall normal turbulent intensities in inner scaling $(-)$

$\left\langle\bar{u}_{r m s}^{+}\right\rangle,\left\langle\bar{v}_{r m s}^{+}\right\rangle$double averaged streamwise and wall normal turbulent intensities in inner scaling $(-)$

$-\left\langle\overline{u^{\prime} v^{\prime}}\right\rangle$ double averaged Reynolds shear stress $\left(\mathrm{m}^{2} / \mathrm{s}^{2}\right)$

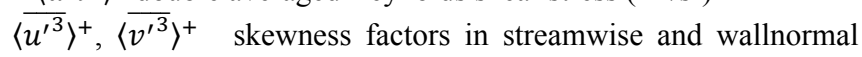
directions with $u_{*}$ as the scaling variable

$\left.\left.\left(\left\langle\overline{u^{\prime 3}}\right\rangle^{+}=\frac{\left\langle\overline{{u^{\prime}}^{3}}\right\rangle}{u_{*}^{3}}, \overline{\left\langle{v^{\prime}}^{3}\right.}\right\rangle^{+},=\overline{\left\langle{v^{\prime}}^{3}\right.}\right\rangle / u_{*}^{3}\right)(-)$

$D_{u *}=\left\langle\overline{u^{\prime} v^{\prime 2}}\right\rangle^{+}, D_{v_{*}}=\left\langle\overline{u^{\prime 2} v^{\prime}}\right\rangle^{+} \quad$ streamwise and wall normal turbulent diffusion factors scaled with friction velocity $(-)$

$D_{u, r m s}=\left\langle\overline{u^{\prime} v^{\prime 2}}\right\rangle / u_{r m s} v_{r m s}^{2} \quad, \quad D_{v, r m s}=\left\langle\overline{\left\langle u^{\prime 2} v^{\prime}\right.}\right\rangle / u_{r m s}^{2} v_{r m s}$ streamwise and wall normal turbulent diffusion factors scaled with turbulent intensities $(-)$

$S_{u}, S_{v}$ skewness factors in streamwise and wallnormal directions with $U_{\max }$ as the scaling variable $\left(S_{u}=\left\langle\overline{u^{\prime 3}}\right\rangle / U_{\max }^{3}\right)$, $\left.S_{v}=\left\langle\overline{{v^{\prime}}^{3}}\right\rangle / U_{\text {max }}^{3}\right)(-)$

$S_{u}^{*}, S_{v}^{*}$ skewness factors in streamwise and wallnormal directions with $u_{*}$ as the scaling variable $\left.\left(S_{u}^{*}=\frac{\left.\overline{\left\langle{u^{\prime}}^{3}\right.}\right\rangle}{u_{*}^{3}}, S_{v}^{*}=\overline{\left\langle v^{\prime 3}\right.}\right\rangle / u_{*}^{3}\right)(-)$

$S_{u, r m s}, S_{v, r m s}$ skewness factors in streamwise and wallnormal directions scaled with respective $u_{r m s}, v_{r m s}$ intensities $\left(S_{u, r m s}=\left\langle\overline{u^{\prime 3}}\right\rangle / u_{r m s}^{3}, S_{v, r m s}=\left\langle\overline{v^{\prime 3}}\right\rangle / v_{r m s}^{3}\right)(-)$

$S_{Q, H} \quad$ The Reynolds shear stress fractional contribution $\left(S_{Q, H}\right)$ in each quadrant $(-)$

Received 26 November 2015 Accepted 20 May 2016

Note: Colour version of Figures can be found in the web version of this article. 